\title{
EFEITOS DOS PROCESSOS DE SEMEADURA NO STAND DA CULTURA DE DIVERSAS HORTALICCAS
}

\author{
MARIA APARECIDA D. DORIGATTI CRUZ
}

Orientador: Prof. Dr. KEIGO MINAMI

Dissertação apresentada à Escola Superior de Agricultura "Luiz de Queiroz", da Universidade de São Paulo, para obtenção do título de Mestre em AGRONOMIA. Área de concentração: FITOTECNIA.

PIRACICABA

Estado de São Paulo - Brasil

Fevereiro - 1985 
Aos meus pais JOAO E ANGELINA

e $\bar{a}$ aUo SOFIA

OFEREGO

Ao meu esposo RAIMUNDO

$e$ aOs meus filhos: JOAO HENRIQUE

e CARLOS EDUARDO

D $E$ E D I $I C O$ 


\section{A G R A DE C I MENTO}

A AUTORA expressa seus agradecimentos a todas as pessoas e Instituições que, direta ou indiretamente colaboraram para a realização deste trabalho, especialmente:

Ao Prof. Or. KEIGO MINAMI, pela orientação, amizade e constante incentivo durante o curso e na execuçäo deste trabalho;

A ESCOLA SUPERIOR de AGRICULTURA "LUIZ DE qUEIROZ", da UNI VERSIDADE DE SÃO PAULO, Piracicaba, SP, pela oportunidade de aperfeiçoamento;

Ao cNPq I CENTRO NACIONAL DE DESENUOLUIMENTO CIENTIFICO E TECNOLÖGICO) e à CAPES (COORDENAÇÃO DE APERFEIÇOAMENTO DE PES SOAL DE NIVEL SUPERIORI, pelas ajudas financeiras concedidas;

AOS PROFESSORES DO DEPARTAMENTO DE AGRICULTURA E HORTICULTU RA, pelos ensinamentos transmitidos;

Ao meu esposo RAIMUNDO, pelo esforço e participação constan te, principalmente nos momentos mais dificeis;

AOS COLEGAS DO CURSO DE POS-GRADUAÇAO, pelo incentivo, amizade e sugestões durante o curso; 
AOS FUNCIONARIOS DO SETOR DE HORTICULTURA, pela colaboração na execução do experimento;

AOS FUNCIONARIOS DA BIBLIOTECA DA ESALQ-USP, em especial aO Sr. LUIZ CARLOS VERISSIMO, pela solicitude no atendimento. 
$\widetilde{I} N D$ I C E

Pãgina

RESUMO $\ldots \ldots \ldots \ldots \ldots \ldots \ldots \ldots \ldots \ldots \ldots \ldots \ldots \ldots \ldots \ldots \ldots \ldots$

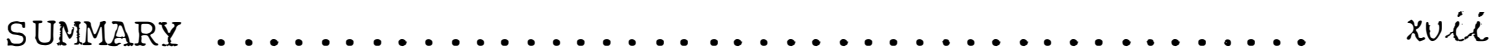

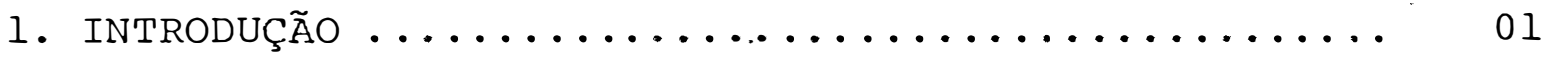

2. REVISÃO DE LITERATURA $\ldots \ldots \ldots \ldots \ldots \ldots \ldots \ldots \ldots \ldots \ldots \ldots \ldots \ldots$

2.1. MEtodos QUe UtilizAM A SEMENTE ............ 04

2.2. METODOS QUE UTILIZAM MELHORAMENTO DO SOLO .... 13

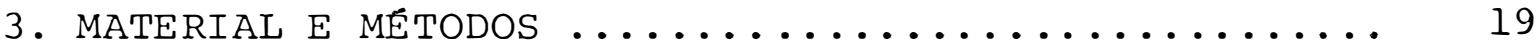

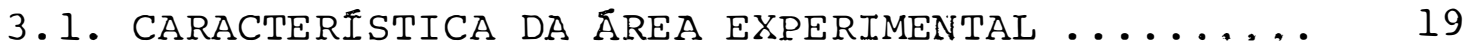

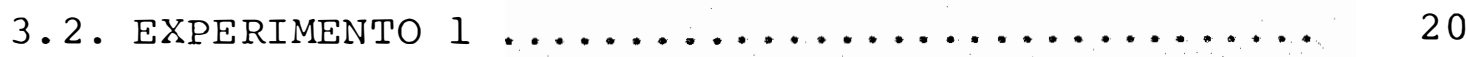

3.2.1. Tratos culturais .............. 20

3.2.2. Preparo das sementes e semeadura ..... 21

a) Pré-germinação ............... 21

b) Semeadura .................. 22

b.1) Semeadura em gel $\ldots \ldots \ldots \ldots \ldots \quad 22$

b.2) Semeadura com vermiculita .... 22

b.3) Semeadura convencional ....... 23

3.2.3. Delineamento experimental e tratamentos 23

3.2.4. Avaliação .................. 24 
Pāgina

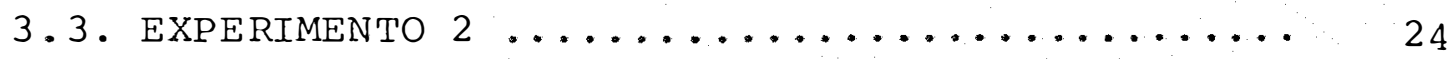

3.3.1. Tratos culturais ............... 25

3.3.2. Preparo das caixas para semeadura .... 25

a) Caixas com solo ................ 25

b) Caixas com vermiculita e matéria or

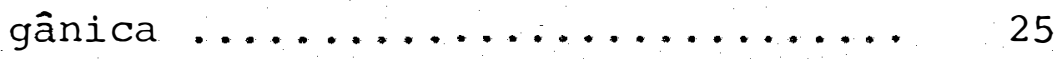

3.3.3. Preparo de sementes e semeadura ...... 26

3.3.4. Delineamento experimental e: tratamen

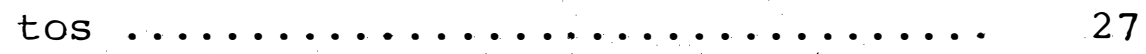

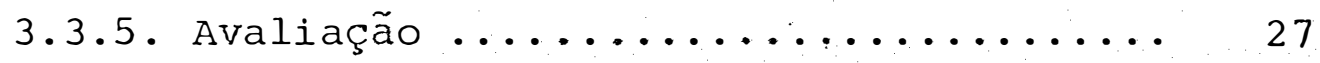

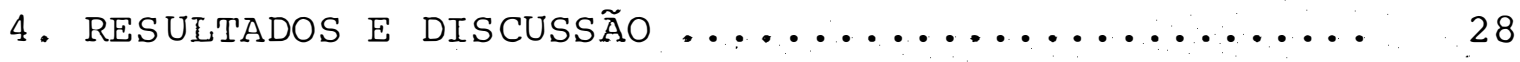

4.1. PARA A FASE DE CAMPO, SEMEADURA NO SOLO .... 28

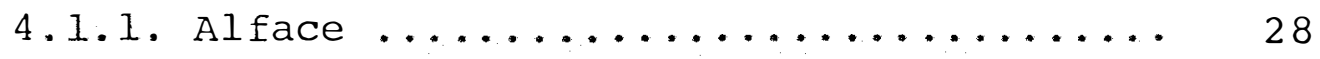

4.1 .2 . Tomate $\ldots \ldots \ldots \ldots \ldots \ldots \ldots \ldots \ldots \ldots \ldots \ldots \ldots \ldots \ldots$

4.1 .3$. Repolho ....................... 35

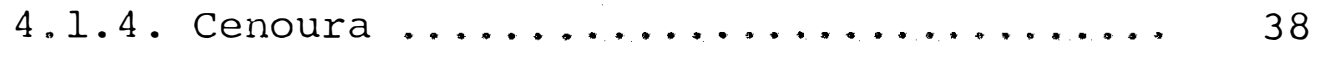

4.2. PARA A FASE DE CAMPO, SEMEADURA EM CAIXAS ... 38.

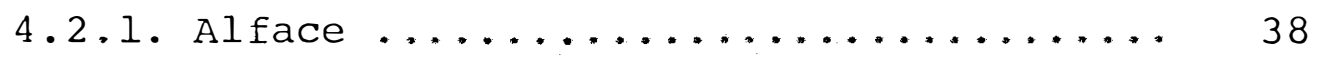

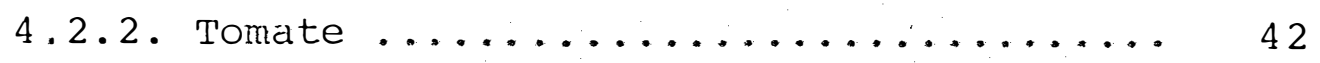

4.2 .3$. Cenoura ....................... 45

4.2 .4$. Cebola $\ldots \ldots \ldots \ldots \ldots \ldots \ldots \ldots \ldots \ldots \ldots . \ldots . \ldots 4$ 
4.3. CONSIDERAÇÕES GERAIS ................... 5 ].

5. CONCLUSÕES .......................... 53

LITERATURA CITADA ......................... 55

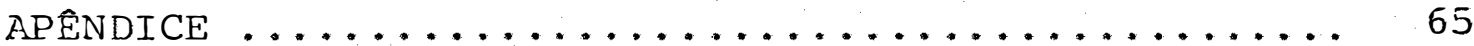




\section{LISTA DE TABELAS}

Pāgina

TABELA 1. Nümero de seedlings emergidos por tratamento e por repetições, de alface cv White Bos ton, em condições de campo ..............

TABELA 2. Porcentagem de emergência de seedlings e porcentagem total de emergência em campo e - tempo para 50\% de emergência de sementes de alface, cv White Boston, semeadas em 31/ $108 / 1982 \ldots \ldots \ldots \ldots \ldots \ldots \ldots \ldots \ldots \ldots \ldots \ldots \ldots \ldots \ldots$

TABELA 3. Quantidade de seedlings emergidos por trata mento e por repetição, de tomate cv Santa Cruz Kada, em condições de campo ..........

TABELA 4. Porcentagem de emergência diāria de seedlings, porcentagem total de emexgência em campo e o tempo para 50\% de emergência (T50), para tomate cv Santa Cruz Kada, semeado em $26 / 08 / 1982 \ldots \ldots \ldots \ldots \ldots \ldots \ldots \ldots \ldots \ldots \ldots \ldots \ldots \ldots$

TABELA 5. Quantidade de seedlings emergidos, por tratamento e por repetições, de repolho cv hí-

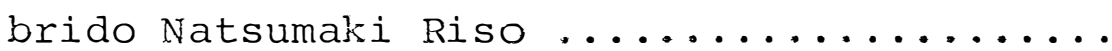


TABELA 6. Porcentagem de emergência diäria de seedlings, porcentagem total de emergência em campo e o tempo para 50\% de emergência (T50) de repolho cv Natsumaki Riso. Semea dura realizada em $25 / 08 / 1982 \ldots \ldots \ldots \ldots$

TABELA 7. Quantidade de seedlings emergidos, por tratamentos e por repetições, de alface cv Ba-

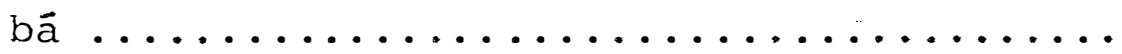

TABELA 8. Porcentagem de emergência diāria de seed lings, porcentagem total de emergência em campo e o tempo para se obter $50 \%$ de emergência de sementes de alface cv Babā, semea das em $06 / 04 / 1984 \ldots \ldots \ldots \ldots \ldots \ldots \ldots \ldots \ldots \ldots \ldots \ldots \ldots \ldots \ldots \ldots$

TABELA 9. Quantidade de seedlings emergidos, por tratamentos e por repetições, de tomate cv

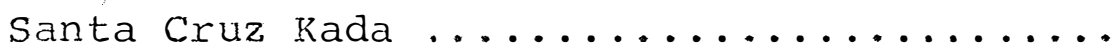


TABELA 10. Porcentagem de emergência diária de seedlings, porcentagem total de emergência de sementes e o tempo para se ter 50\% de emergência de seedlings de tomate cV Santa Cruz Kada. Semeadura de sementes pre-germinadas: $12 / 04 / 1984$ e a semeadura de se-

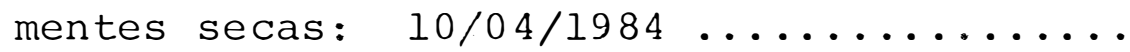

TABELA 11. Quantidade de seedlings emergidos, por tratamentos e por repetições, de sementes de

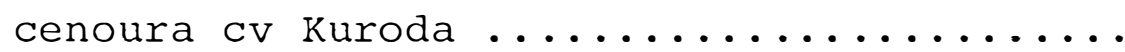

TABELA 12. Porcentagem de emergência diäria de seedlings, porcentagem total de emergência de seedlings e o tempo para se atingir 50\% de emergência de sementes de cenoura cv Kuroda. Semeadura $: 10 / 04 / 1984 \ldots \ldots \ldots \ldots \ldots$

TABELA 13. Quantidade de seedlings emergidos por trata tamento e por repetições, de cebola cv Pira

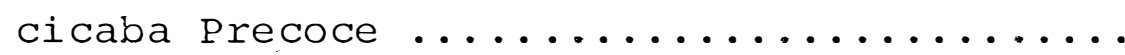


TABELA 14. Porcentagem de emergência diária de seed lings, porcentagem total de emergência de seedlings e o tempo para se atingir $50 \%$ de emergência de sementes de cebola cv Piracicaba Precoce. Semeadura: 10/04/1984 .....

TABELA 15. Dados meteorológicos dos meses de agosto/se tembro de 1982, ESALQ, Piracicaba-SP, duran te o período em que foram realizados os experimentos $\ldots \ldots \ldots \ldots \ldots \ldots \ldots \ldots \ldots$

TABELA 16. Dados meteorológicos dos meses de abril e maio de 1984, ESALQ, Piracicaba-SP, durante o período em que foram realizados os experi

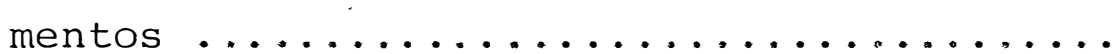




\section{LISTA DE FIGURAS}

Página

FIGURA 1. Porcentagem de emergência diária de seedlings de alface cv White Boston, em condi ções de campo, semeadas em 31/08/1982 .....

FIGURA 2. Porcentagem de emergência diária de seedlings de tomate cv Santa Cruz Kada, em condições de campo, semeadas em 26/08/1982 ...

FIGURA 3. Porcentagem de emergência diária de seedlings de repolho cv Natsumaki Riso, em condições de campo. Semeadura em 25/08/1982.

FIGURA 4. Porcentagem de emergência diária de seedlings de alface cv Babá, semeada em 06/04/ $/ 1984 \ldots \ldots \ldots \ldots \ldots \ldots \ldots \ldots \ldots \ldots \ldots \ldots \ldots \ldots \ldots \ldots \ldots \ldots$

FIGURA 5. Porcentagem de emergência diária de seedlings de tomate cv Santa Cruz Kada. Semeadura de sementes secas: 10/04/1984 e de se mentes prë-germinadas: 12/04/1984 ....... 
FIGURA 6. Porcentagem de emergência diária de seedlings de cenoura cv Kuroda. ... Semeadura :

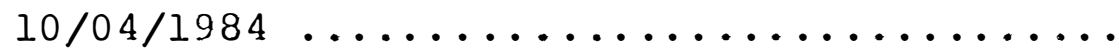

FIGURA 7. Porcentagem de emergência de seedlings de cebola cv Piracicaba Precoce, semeada :em

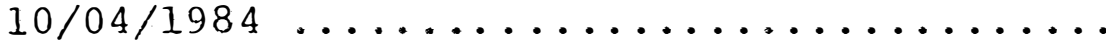




\title{
EFEITOS DOS PROCESSOS DE SEMEADURA NO STAND DA CULTURA DE DI VERSAS HORTALIÇAS
}

\author{
MARIA APARECIDA D, DORIGATTI CRUZ \\ Orientador: Pró. Or. KEIGO MINAMI
}

\section{RESUMO}

Com a finalidade de verificar o efeito de diferentes métodos de semeadura no stand de várias hortaliças, foi instalado um experimento no campo experimental do setor de Horticultura da Escola Superior de Agricultura "Luiz de Queiroz", em Piracicaba, SP.

O experimento foi realizado em duas épccas: a primeira, nos meses de agosto-setembro, sendo a semeadura dire ta no campo; a segunda, realizada no mês de abril, onde as semeaduras foram feitas em caixas de madeira, com uma área total de $0,084 \mathrm{~m}^{2}$ para cada parcela.

Na primeira época, as hortaliças usadas foram: alface cv White Boston; tomate cv Santa Cruz Kada; repolho CV. Natsumaki Riso e cenoura CV Kuroda.

Foram utilizadas para alface: 100 sementes por metro linear; para tomate: 160 sementes por metro linear; para repolho: 6 sementes por cova e para cenoura: 100 semen- 
tes por metro linear. Os tratamentos compreenderam: sementes secas e pré-germinadas diluídas em gel de silicato de magnésio e em vermiculita, sendo comparadas com sementes secas semeadas convencionalmente.

Os lotes de sementes eram diluídos em 1 litro de gel, homogeneizados.

A vermiculita foi usada na proporção de 11 para 1 (1l $\mathrm{kg}$ de vermiculita : $1 \mathrm{~kg}$ de semente).

Na segunda época, foram utilizadas as seguintes hortaliças: alface cv Babä; tomate cv Santa Cruz Kada; cenoura cv Kuroda e cebola cv Piracicaba Precoce.

Os tratamentos utilizados compreendiam: sementes secas e pré-germinadas, diluídas em gel e semeadas no. solo; sementes secas e pré-germinadas, semeadas no solo e semen tes secas e pré-germinadas, semeadas no substrato: vermiculita-matéxia orgânica.

Os lotes de sementes continham em média, 414 sementes para alface; 366 sementes para cenoura; 152 sementes para tomate e 216 sementes para cebola.

O substrato vermiculita-matéria orgânica, foi utilizado na proporção de 1:l, sendo usado o esterco de curral co mo matēria orgânica.

A avaliaçãó foi realizada através da contagem diāria de emergência de seedlings, sendo avaliado tambēm, o 
tempo para se atingir 50\% de emergência $\left(\mathbb{T}_{50}\right)$.

De uma maneira geral, os tratamentos cujas semen tes foram diluídas em gel ou vermiculita, apresentaram melhores resultados quanto à quantidade de seedlings emergidos, além do gel e da vermiculita facilitarem a semeadura.

A adição da matéria orgânica à vermiculita, só beneficiou as sementes de cenoura, cV. Kuroda.

Em relação à emergência total, a pré-germinação foi tão eficiente quanto a semente seca, para a semeadura com gel ou vermiculita, desde que não haja matéria orgânica. 


\title{
EFFECTS OF SOWING PROCESS IN THE STAND OF SEVERAL VEGETABLE CROPS
}

\author{
MARIA APARECIDA D. DORIGATTI CRUZ \\ Adviser: Pro6. Dr. KEIGO MINAMI
}

SUMMARY

To verify the effect of seeding method on vegeta ble stand it was done an experiment in the Experimental Area of the Horticulture Section of Escola Superior de Agricultura "Luiz de Queiroz", University of S. Paulo, in Piracicaba (SP), Brazil.

The experiment was realized in two periods. One was done in august-september, sowing diretly in the field; the other was done in april-may, the sowing was done in wood boxes, with a total area of $0,084 \mathrm{~m}^{2}$ for plot.

In the first period, the vegetables used were: lettuce cv white Boston; tomato cv Santa Cruz Kada; cabbage CV Natsumaki Riso and carrot cv Kuroda.

The treatments for the first period were pregerminated and dry seed diluted in an magnesium silicate gel and vermiculite, being compared with dry seed sowed conventionally 
The gel was used at the rote of 1 옹

The vermiculite used at the rote $11: 1$ ( $1 \mathrm{~kg}$ of vermiculite by one $\mathrm{kg}$ of seed).

In the second period, it was used the following vegetables: lettuce Cv Babá; tomato cv Santa Cruz Kada; car rot CV Kuroda and onion cV Piracicaba Precoce.

The treatments used consisted of: dry and pregerminated seeds diluted in the gel; $d_{r y}$ and pre-germinated seeds and dry and pre-germinated seeds using the vermiculite organic matter media.

The vermiculite - organic matter media, was used in the rote: of $1: 1$ and the organic matter was used catte manure.

The avaliation was realized through dayly counting of the emergence of seedlings. It was also determined the days of 50 percent emergence $\left(\mathrm{T}_{50}\right)$.

In a general matter, the treatments that the seeds were diluted in gel or vermiculite presented the best results for the number of emerged seedlings, beyond it the gel or vermiculite to facilitate the sowing.

The addition of organic matter in the vermiculite has improved only the seeds of carrot.cv. Kuroda.

All that the total emergencem the pre-germination 
was efficient as much as the dry seed for the gel or vermiculi te sowing, since organic matter is not used. 


\section{INTRODUÇÃO}

As plantas olerícolas têm inestimável valor alimentício, principalmente, devido ao fornecimento de vitaminas e sais minerais.

Seu cultivo no Brasil, antes feito em áreas rela tivamente próximas dos grandes centros, hoje, dada a melhoria de transporte e devicio às terras pröximas dessas áreas estarem sendo usadas para explorações imobiliārias, está sendo conduzido em zonas mais distantes, com certa tendência à especialização e maiores :extensões.

Principalmente nos Estados de São Paulo, Rio Gran de do sul e Minas Gerais, a produção de hortaliças constitui-se numa atividade importante, em plena expansão, para atender a maior procura desses produtos "in natura", destinados ao consu mo interno e à industrialização.

A característica mais maxcante na produção de hortaliças e o seu caräter intensivo, no que se refere à uti 
lização da área, tratos culturais, da mão-de-obra e dos insumos modernos que devem ser bem aproveitados, para haver um maior lucro. Porém, um sério problema ocorre na produção de muitas hortaliças, ou seja, o estabelecimento do stand, principalmente daquelas onde as sementes são de difícil individualidade . Para o estabelecimento do stand dessas hortaliças, é necessā rio usar um excesso de sementes que, apōs emergidas, serão des bastadas. Esta operação, além de causar injūrias às plantas restantes e variaçöes nas produções, utilizam maior quantidade de mão-de-obra, para esta prática, e também perdas das plantas onerando, assim o seu custo.

Outro problema que ocorre é com relação à germinação que pode variar significativamente, por serem as semen:tes de algumas hortaliças, muito sensíveis às condições ambien tais, que podem reduzir a germinação e impedir a emerçência.

Para contornar estes problemas, tem-se usado mé-todos que utilizam desde uma simples classificação de sementes, até processos como: peletização de sementes, diluições de sementes em diluentes sólidos como a vermiculita ou líquidos como certos géis, também o uso de substratos para se conseguir melhores emergências de seedlings e, portanto, o estabelecimen to do stand desejāvel destas culturas.

Neste trabalho, o objetivo proposto é verificar corro vārios processos de semeadura atuam na porcentagem de emergência de seedlings e no tempo para ser atingido 50\% de emergência, para diversas hortaliças. 


\section{REVISÃO DE LITERATURA}

O estabelecimento do stanci aderuario é um dos maiores problemas que ocorrem na produção de muitas plantas econômicas, principalmente daquelas onde as sementes são muito peque nas e de difícil individualização.

A germinação pode variar significativamente atë dentro de um simples lote de sementes, principalmente sementes de hortaliças, as quais são muito sensíveis às condições ambientais. Temperaturas abaixo do mínimo ou acima do mäximo de tolerância, formação de crosta do solo, profundidaçe de semeadura, ataque de microorganismos, etc, reduzem a germinação e impedem a emergência.

Um bom stand. de cultura é correntemente obtido pela semeadura de excesso de sementes e posterior desbaste, de plantas para ser conseguido o espaçamento desejado depois da emergência. As práticas de desbaste podem injuriar as plantas remanescentes e causar variação na produção. 
Vários métodos, portanto, têm sido usados na tên tativa da melhora da emergência de seedlings no campo; dentre eles inclūem-se os relativos a semente diretamente e outros relativos a melhoria do solo.

\subsection{METODOS QUE UTILIZAM A SEMENTE}

Dentre estes mëtodos, inclui-se a classificação de sementes. COELHO et alii (1973), estudando a influência do tamanho da semente de quiabo cv Chifre-de-veado na sua per formance, verificaram em casa-de-vegetação, que as sementes classificadas nos maiores tamanhos, tenderam geralmente a um melhor comportamento quanto à emergência. Em condições de campo, porém, não obtiveram tais diferenças e concluíram não haver necessidade, portanto, de classificar as sementes de quiabo. O mesmo foi verificado por VIGGIANo et alie (1973), com sementes de tomate cv Miguel Pereira.

GRAY (1978), classificando as sementes de alface em pesadas, leves e não classificadas, não obteve efeito significativo no final da porcentagem de emergência dos seedlings.

Porém, DIAS (1978) constatou que, no teste de germinação de sementes de arroz, houve influência do peso de sementes, sendo que houve melhoria na emergência de sementes mais pesadas. 
Outros trabalhos mostram a melhoria da germinação de sementes por soluções químicas; dentre eles o ácido giberélico é citado por KAHN (1960), que obteve melhora na germinação de sementes de alface. SKINNER e SHIVE (1959) uti zando 6-benzilamina purina sozinha ou em mistura com o ácido giberélico, obtiveram também melhoria na porcentagem de germi nação de sementes de alface.

O uso do umedecimento de sementes em sais como $\mathrm{KNO}_{3}+\mathrm{K}_{3} \mathrm{PO}_{4}$, antes do plantio, tem resultado em adiantamento na emergência de seedlings em campo, como relatado por ELLS (1973); VAN DOREN e HENRY (1973); BUSSELL e GRAY (1976) e GRAY e STECKEL (1977).

Imersão de sementes em soluções de tiourëia ou água somente, tem melhorado a germinação de sementes de chicó ria, quando estas foram tratadas por um periodo de 8 horas, a $18^{\circ} \mathrm{C}$ (THOMPSON , 1946 ).

PAULI e HARRIOTT (1968) obtiveram em campo, acima de $90 \%$ de emergência de sementes de alface, quando estas foram tratadas com uma solução de 25 ppm de cinetina.

WOLEE e SIMS (1982), trabalhando com sementes de tomate cv UC-82 pré-molhadas em uma solução de polietileno glicol (PEG), por um período de 7 dias, antes do plantio, tiveram uma taxa mais rápida de emergência de seedlings. 
As sementes são normalmente pequenas e de baixa densidade, tornando difícil sua individualização para plantio, necessitando, portanto, grande quantidade de sementes para conseguir um stand desejado.

ZINK (1955), para aumentar o tamanho das sementes de alface, peletizou-as, isto é, envolveu-as com um material poroso, no caso, a argila montmorilonita, adicionando também a ela, materiais como: tiouréia, terramicina, vermicu lita e krilium. As sementes, por este método, foram aumentadas cerca de 60 vezes em seu peso. Porém, as sementes não peletizadas tiveram maior porcentagem na germinação do que se mentes peletizadas.

Trabalhos desenvolvidos por ROBINSON e WORKER (1966), que estudavam vários fatores que afetavam a emergência da beterraba, notaram que coberturas das sementes por per lita e calcáreo, não afetaram significativamente a emergência dos seedlings. Quando usaram a irrigação por aspersão obtive ram um total de $60 \%$ na germinação.

MILIER e SOOTER (1967), sabendo dos problemas relacionados à peletização, verificaram que: a) o material para peletização deveria ser poroso para permitir a entrada de ar até a semente; b) deveria ser solüvel em contato com a ăgua; c) não ser töxico; d) aplicaṽeis a bases comerciais. Com estes dados, estudaram a possibilidade de alguns materiais serem usados para tais fins e notaram que a argila usada no 
processo de peletização de sementes de algumas hortaliças, re duzia a taxa de emergência e a emergência total; porëm, a por centagem de emergência era aumentada quando nas sementes peletizadas eram queirrados os envoltórios das mesmas. Outros mate riais usados, como a argila e solução de açūcar, aumentaram a emergência de seedlings em relação às não tratadas.

IRMAN (1968) usou somente a taxa de cobertura de 5:1 ou 10:1 (sendo 5 ou 10, partes do material, para 1 de sementes); porém, não citou o material usado. Com estas taxas de cobertura conseguiu um pequeno aumento na porcentagem de germinação de sementes de alface.

Outros materiais foram utilizados para a cobertura de sementes, destacando-se dentre eles, a vermiculita.

PAULI e HARRIOTT (1968), com sementes de alface envolvidas em cones e discos de vermiculita, obtiveram uma por centagem de emergência de seedlings, acima de 90\%; o mesmo foi conseguido por McCOY et alie (1969), com cobertura de sementes por vermiculita e uso de irrigação por aspersão.

HARRIOTT (1970), fazendo estudo com vārias épocas de plantio, configuração do sistema de tabletes de plantio, sendo os mesmos em formas: cilindrica, cônica ou disco e usando vãrios tipos de irrigação para sementes de alface, constatou que o sistema de tablete não somente prevenia contra competição entre plantas, como também das injürias causadas no desbaste. 
ROBINSON et alii (1975) e ROBINSON e MAYBERRY (1976), obtiveram um ótimo estabelecimento do stand em alfa ce, usando a cobertura de sementes com vermiculita.

Na tentativa de melhoria de germinação de semen tes outras técnicas foram sendo estudadas, dentre elas, a se meadura de sementes pré-germinadas, suspensas em um fluido. O primeiro relato sobre esta tentativa foi descrito por Elliott (1966), citado por GRAY (198.1), o qual usou a pré-germinação de sementes em àgua arejada e a diluição destas sementes em um gel de alginato de södio. Estas sementes ficavam suspensas no gel e, durante a semeadura, eram transportadas pelo gel, até os sulcos. Este processo era feito através de uma semeadeiraque continha um tanque, onde as sementes ficavam suspensas no gel e, através de dispositivos próprios, eram se meadas com precisão. Obteve melhoria no estabelecimento de gramíneas, forrageiras e beterraba açucareira, mostrando, assim, que a técnica poderia ser usada com segurança no plantio direto no campo.

Em 1974, CURRAH et alii tentaram o mesmo proces so usando vārias hortaliças. Para cenoura, conseguiram adian tamento de 5 dias na emergência de sementes prë-germinadas e semeadas com gel. Para alface, não obtiveram diferença no tempo médio da emergência ou no stanā final de plantas, entre plantas provenientes de sementes secas e prë-germinadas. Porém, para aipo, que requer luz na germinação, obtiveram um 
stand de 60 para sementes pré-germinadas e $2 \%$ de sementes secas.

A semeadura líquida, como foi chamada então, é um termo que, segundo GRAY (1981) e TAYLOR et alii (1981), tem sido usado para se referir à semeadura de sementes pré-germinadas, suspensas num gel protetor e liberadas ao solo.

As sementes são germinadas em condições ideais de umidade, temperatura e luz e são suspensas em um gel carre gador e mexidas levemente para não causar danos às radículas e semeadas através de máquinas, ou seja, "semeadoras líquidas" . ou então, atravēs de sacos plästicos, para pequenas quantidades. No saco plástico é feito um furo numa das extremidades por onde há o extravazamento de sementes carregadás pelo gel. As sementes cảem no solo a uma distância mais ou menos constante uma das outras, sendo chamada de semeadura de precisão.

A pré-germinação das sementes tem sido descrita por vários métodos, dentre eles: em papel absorvente, onde as sementes são colocadas e umedecidas para prover às radículas, um bom desenvolvimento (CURRAH et ali.i, 1974; BRYAN e.t alii, 1978); outro método tem sido o de colocar sementes em colunas de vidro por onde circula água arejada (DARBY e SAL TER, 1976); TAYLOR, 1977 e TAYLOR et ali., 1981).

Germinação satisfatôria tem sido obtida através de semeadura líquida, para sementes de vārias hortaliças, usando-se temperaturas entre 18 a $2.5^{\circ} \mathrm{C}$ (CURRAH et alii, 1974; 
BIDDINGTON e.t alii, 1975; GRAY e STECKEL, 1977; TAYLOR, 1977 e GRAY, 1978a',b).

Altas temperaturas têm sido usadas para cebola, de acordo com LIPE e SKINNER (1979) e baixas temperaturas para beterraba açucareira, segundo LONGDEN et alii (1979).

Quanto ao tempo para as sementes germinarem tem sido relatado por TAYLOR (1977), GRAY e SALTER (1980), muito variável entre as espécies, variando de 24 a 48 horas para al face, cenoura, repolho e couve-flor; de 96 a 120 horas para aipo, cebola, pimenta e aspargo.

Hā relatórios também sobre o comprimentó ideal de radículas das sementes prë-germinadas. SALTER (1978a) mos trou que sementes de alface semeadas quando as radículas tinham de 1 a $2 \mathrm{~mm}$ de comprimento, deram uma maior porcentagem de emergência de seedlings do que aquelas com maior ou menor radiculas. LONGDEN et ali. (1979) observaram um aumento na porcentagem e precocidade na emergência de sementes de beterraba, quando o comprimento médio da radícula para semeadura era aumentada de 3 para $8 \mathrm{~mm}$. BUSSELL e GRAY (1976) citaram que um comprimento de radícula de, no mínimo $2 \mathrm{~mm}$, è necessärio para sementes de tomate.

Värios autores têm descrito os efeitos da semea dura líquida de sementes pré-germinadas no estabelecimento do seedling, desenvolvimento e produção de hortaliças. 
Com alface, tem melhorado o estabelecimento de seedlings e reduzido a extensão da emergência quando usada a semeadura líquida (GRAY, 1976; GRAY, 1978a,b). Uma maior uni formidade no tempo de maturação das cabeças de alface, tambēm tem sido conseguida (SALTER, 1978b). Sementes pré-germinadas deram entre 5 a 8 dias mais cedo a emergência, do que as sementes secas (GRAY, 1978a), particularmente quando as tempera turas dó solo estão abaixo de $10^{\circ} \mathrm{C}$, de meados do verão em diante, quando as temperaturas do solo induzem a termodormência (Darby, citado por GRAY, 1981).

GRAY e.t alii (1979) encontraram um adiantamento de cerca de 15 dias na emergência de sementes pré-germinadas de tomate, em semeaduras feitas no final de abril, com as tem peraturas variando de 9 a $11,5^{\circ} \mathrm{C}$ e cerca de 6 dias mais cedo, quando a semeadura foi feita no início de abril, com temperaturas entre 12 a $15^{\circ} \mathrm{C}$. Houve aumento na porcentagem de emergência dos seedlings de ambas as semeaduxas e as produções es tabelecidas pela semeadura líquida, amadureceram cerca de 7 dias mais cedo do que aquelas estabelecidas por sementes secas. Experimentos de campo têm mostrado um aumento na produção de cerca de 35 para 119\%, com técnicas de semeadura liqui da para tomate (GRIMSHAW, 1981).

WOLFE e SIMS (1982) observaram uma redução no T50 (tempo para se ter 50\% de germinação) de sementes de toma te prē-germinadas em semeadura líquida; porēm, tiveram também, 
um significante aumento de frutos vermelhos partidos na colheita.

Com sementes de cebola cv New Mexico White Grano, LIPE e SKINNER (1979) observaram a emergência de seedlings após 7 dias da semeadura para sementes pré-germinadas e 30 dias para sementes secas. O stand de plantas foi estabelecido com sementes pré-germinadas, cerca de 12 dias mais cedo do que com sementes secas. Os autores constataram um adianta mento de 10 a 12 dias na colheita e um aumento de 37,5\% no diâa metro do bulbo desenvolvido de sementes pré-germinadas. Porém, resultados com cebola cv Rijnsburger, têm sido variáveis (TAYLOR, 1977) .

Semeadura liquida de sementes pré-germinadas de salsão tem dado um adiantamento e um aumento na emergência de seedlings, quando comparadas com sementes secas ( CURRAH et alii, 1974; BIDDINGTON et alii, 1975 e TAYLOR, 1977).

Com a variedade Flórida 683 de aipo, BIDLINGTCN et alie (1975) e TAYLOR (1977) encontraram uma emergência de cerca de $60 \%$ de sementes semeadas pré-germinadas, em comparação a 6\% de sementes secas. SALTER (1978b), trabalhando com cinco diferentes cultivares de aipo em semeadura liquida de sementes pré-germinadas, encontrou um adiantamento de 21 dias na emergência de seedlings.

Para cenoura, SALTER (1978b) verificou com semeadura liquida, que os seedlings emergiram de 5 a 12 dias 
mais cedo, e observou também, um aumento de $20 \%$ na porcentagem de emergência, com a temperatura do solo a 99 C.

Outras hortaliças como aspargo e pimenta, também têm resultado numa redução no T50, quando suas sementes são pré-germinadas (TAYLOR, I977).

Deve-se ressaltar, porēm, que hā desvantagem no uso de sementes pré-germinadás, quando estas forem semeadas e logo após ocorrer extensos períodos de seca, pois, as sementes prē-germinadas podem sofrer mais injūrias do que as sementes secas (TAYLOR, 1977).

2.2. MÉTODOS QUE UTILIZAM MELHORAMENTO DO SOLO

Outra alternativa usada para o melhoramento da germinação e produção de plantas, tem sido o uso de substratos.

Na floricultura, meios como turfa, esfagno e vermiculita são largamente usados. O uso destes meios tem al terado as propriedades do solo. A adição de vermiculita tem aumentado a quantidade de $\mathrm{K}$ no solo e na planta (DUNHAM, 1967 e BOODLEY e SHELDRAKE JR., 1969) e a adição de turfa e esfagno tem diminuido a quantidade de K (DUNHAM, 1967).

Estes meios têm sido usados sozinhos, misturados com o solo ou então, em combinações. 
A areia é outra alternativa para melhorar o tipo do leito. MEDINA e COUTO (1971), trabalhando com terra ar gilosa, areia e mistura (50\% terra, 50\% areia), verificaram que a areia melhora o meio para a germinação do quiabo.

A mistura de diferentes meios tem sido utilizada para a produção de flores, enraizamento de estacas e prodú ção de hortaliças. KOSTEWICZ e LOCASCIO (1976) e GULL et alii (1977) obtiveram sucesso na produção de tomate com o uso de 1:l em volume de turfa e solo e l:l de mistura de turfa-vermi culita.

Para estaquia de erva-mate, HIGA (1982) utilizou-se de uma mistura de areia e vermiculita, na proporção de 1:1, juntamente com uma concentração de 5000 ppm de IBA dí luído em talco e no substrato, conseguindo 60\% de enraizamento de estacas proveniente de mudas.

De acordo com Moreira e Mimani, citados por MINAMI (s.d.), para o enraizamento de Hidrangea hortencia a ver miculita pura é melhor do que a mistura de vermiculita-solo argiloso-terriço. Para o enraizamento de estacas de bico-de- papagaio (Euphorbia pulcherrima), a mistura de esfagno (50\%) e vermiculita (50\%) deram ötimos resultados (Seeley e Paut, citados por MINAMI, s.d.).

MINAMI (s.d.) recomenda ainda, outros meios para enraizamento de estacas como: vermiculita-areia ( $1: 1$ em volume); vermiculita-xaxim-areia (1:1:1 em volume). 
STILL (1977), na produção de crisântemos, utilí zou-se de vārios meios: uma mistura de solo-turfa-perlita ; casca de pinus e areia, em vārias proporções: 2:1; 3:1; 4:1; 5:1 e 100\% de casca e mistura comerciais, constituídas de misturas de casca de pinus, turfa e vermiculita. Os meios constituídos de casca-areia (3:1 ou 2:1 em volume), foram com paráveis às misturas comerciais, porém, o meio constituído de 100\% de casca de pinus ou solo-turfa-perlita, reduziram signi ficativamente a altura da planta.

No Brasil, vārios trabalhos realizados utilizan do terra, esterco, areia, terriço e suas combinações, ou seja: a) 4 terra; b) 3:1 terra-esterco; c) 2:1:1 terra-esterco-areia; d) 1:1:1:1 terra-esterco-areia-terriço; e) 1:2:1 terra-esterco-areia; f) 2:1:1 terra-esterco-terriço, mostra ram que nos tratamentos utilizando-se somente terra (a), as mudas de couve-flor, tomate e cebola foram as de pior qualida de. Os melhores resultados de germinação de couve-flor, segundo FERREIRA et alii (1977a), foram naqueles tratamentos que continham menor proporção de terra, ou seja, d e $\underline{f}$. Para tomate, os tratamentos que obtiveram maior porcentagem de ge $\underline{\underline{r}}$ minação foram aqueles onde a areia fez parte da sementeira (ㄷ, $\underline{\mathrm{d}}$ e $\underline{\mathrm{e}})$. O tratamento $\underline{\mathrm{b}}$, composto de 3 partes de terra e 1 de esterco, produziu o maior número de muda, tipo excelente (FETRßE RA et alii (1977b). FERREIRA e AGUIAR (1978), na produção de cebo la, obtiveram resultados semelhantes aos trabalhos acima rela- 
cionados, ou seja, o tratamento só com solo produziu mudas de qualidade inferior. Quanto aos demais tratamentos comporta-ram-se de maneira semelhante quanto ao número e qualidade de mudas produzidas, sendo que os tratamentos $\underline{\mathrm{c}} \mathrm{e} \underline{\mathrm{e}}$, onde o esterco e a areia fizeram parte da sementeira, apresentaram ten dências para produzir melhores mudas e maior produção de bulbos no campo.

DIAS (1973) estudou a aplicação de vārias mistu ras para a produção de Eucaliptus grandis, sendo que as mistu ras utilizadas foram: solo de mata + solo de cerrado e a com binação destes com esterco de curral e vermiculita. Verificou que o esterco de curral pode ser substituído com sucesso pela vermiculita, em alfobres, na produção de E. grandis. Oḅ servou tambēm, que no solo de mata, a adição de vermicülita ofereceu melhores condições de crescimento às mudas de $E$. grandis do que o esterco, sendo que no solo de cerrado o efei to da vermiculita foi semelhante ao do esterco.

FERNANDES (1983), utilizando-se de bandejas de isopor para produção de mudas de E. saligna, verificou que o melhor substrato para este fim foi aquele constituído de 2 partes de terra e uma parte de vermiculita de textura fina.

MINAMI (s.d.) diz que a vantagem da vermiculita como meio de germinação de sementes, ẻ poder reduzir o nümero de regas, sem afetar a disponibilidade de ăguas às plantas, sendo que para se fazer o transplante e a repicagem, as mudas 
são facilmente destacadas.

Outras combinações com vermiculita têm sido usa das. SCHOEN e KRAMER (1980), usando de combinações de 2 tipos de areia e duas graduações de vermiculita (grossa-média), verificaram que, para emergência de sementes, a melhor combinação foi aquela onde a areia lavada ficava sem pequenas par-tículas e independente do tipo era usada com vermiculita grossa.

FREY (1981), utilizando proporções com solo de 25\%, 50\%, 75\% ou 100\% de vermiculita e vārias hortaliças, verificou as seguintes porcentagens de germinação: para tomate cv Tiny Tim não houve diferenças significativas na germinação entre os tratamentos; para pepino cv Poinsette a germinação foi aumentada de 88,0 a $91,2 \%$ em 25\%, 50\% e 75\% do composto e foi de 83,5\% em vermiculita sozinha, para pimenta doce cv Large Cherry, a germinação foi aumentada 89,2\% em vermiculita sơzinha e decresceu com a adição do composto.

ROCHELLE e VELLO (1982), para a germinação de sementes e desenvolvimento de plântulas de cultivares de cucurbitāceas e, utilizando-se de substratos como: guartzo, areia de rio e vermiculita em 3 ambientes: campo (pleno sol), ripado (meia sombra) e casa-de-vegetação, verificaram que os substratos areia de rio e vermiculita foram superiores ao quartzo; em ambientes fechados, a casa-de-vegetação foi supe rior ao do ripado; e, de campo, quando os substratos foram vermiculita e areia de rio. 
Ewert, citado por MINAMI (s.d.) cita que o subs trato que mais beneficia a maioria das sementes é aquele proveniente da mistura de material orgânico (xaxim, esfagno, esterco) mais vermiculita e cobrir as sementes com uma camada de vermiculita pura.

BATAL et alii (1983), utilizando-se de turfa co mo meio, semearam sementes de brócolo cv Green Duke e Bravo, através da semeadura líquida. As sementes eram divididas em duas classes: pré-germinadas e sem germinação. Alguns lotes de sementes pré-germinadas ainda receberam tratamentos químicos com Tetraclor (quintozene) + capton (à base de 5 gramas) por litro de gel fluído. Obtiveram um adiantamento na emergência de sementes provenientes de sementes pré-germinadas ; porém, os lotes que foram tratados com produtos químicos atra saram a emergência. 


\section{MATERIAL E MÉTODOS}

\subsection{CARACTERISTICA DA ÅREA EXPERIMENTAL}

o experimento foi conduzido na ārea experimental do Setor de Horticultura, do Departamento de Agricuitura e Hor ticultura da Escola Superior de Agricultụra "Luiz de Queiroz", em Piracicaba, São Paulo, Brasil.

O solo utilizado para ambos os experimentos, segundo RANZANI et alii (1966), foi classificado como LatossoloVermelho-Escuro-Orto, série "Luiz de Queiroz".

Segundo SETEZER (1966), de acordo com a classifi cação de Köeppen, o clima da região é do tipo Cwa, ou seja, me sotérmico úmido tropical, com inverno seco. As informações agrometeorológicas do local foram fornecidas pelo Departamento de Física e Meteorologia da ESALQ, sendo: longitude $47^{\circ} 38^{\prime} 00^{\prime \prime} \mathrm{W}$, latitude $22^{\circ} 42^{\prime} 09^{\prime} \mathrm{s}, \mathrm{com}$ altitude média de $540 \mathrm{~m}$.

As médias de temperaturas, precipitações e umida des relativas durante o transcorrer do experimento, encontram- 
-se nas tabelas 15 e 16 (no apêndice).

Foram instalados dois experimentos, sendo 019 realizado em agosto-setembro de 1982, com a semeadura feita no campo diretamente e um 2\%, em abril-maio de 1984, sendo a semeadura realizada no campo, porēm, em caixas de madeira.

\subsection{EXPERIMENTO 1}

As hortaliças utilizadas neste experimento foram: alface cv White Boston, com 48\% de germinação; repolho cv híbrido N.atsumaki Riso, com 75\% de germinação; tomate cv Santa Cruz Kada, sendo a germinação de $45 \%$ e cenoura cv Kuroda, com $53 \%$ de germinação.

A determinação das porcentagens de germinação foi feita em laboratório, segundo a Regra de Análise de Semen tes.

As quantidades de sementes usadas foram: 100 se mentes por metro linear para alface; 6 sementes por cova para repolho; 160 sementes por metro linear para tomate e 100 sementes por metro linear para cenoura.

\subsubsection{Tratos culturais.}

Antes da semeadura foi realizada uma adubação bá sica, utilizando-se: $50 \mathrm{~g}$ de sulfato de amônio, $50 \mathrm{~g}$ de super 
fosfato simples; $30 \mathrm{~g}$ de cloreto de potássio e 201 de esterco de curral curtido, por metro quadrado, para alface, cenoura e tomate e por 5 covas de repolho.

Para o controle de plantas daninhas aplicou-se o herbicida Roundap (Glyphosate) em pré-plantio das culturas e pós-emergência da tiririca (Cyperus rotundus). Durante : 0 transcorrer do experimento, não foi realizado mais nenhum controle.

Para manter a umidade do solo foram utilizadas irrigações por aspersão, nas seguintes datas: 01/09; 08/09; $11 / 09$ e $14 / 09$.

\subsubsection{Preparo das sementes e semeadura}

\section{a) Pré-germinação}

A pré-germinação das sementes foi realizada no laboratório do Setor de Horticultura da Escola Superior de Agricultura "Luiz de Queiroz".

O método utilizado foi descrito por DARBY e SALTER (1976) e TAYLOR (1977) e adaptado às nossas condições, assim, lotes de sementes foram colocados dentro de pequenos sacos de panos e postos a germinar em um balde com água corrente, fresca e arejada.

Os tempos para a pré-germinação foram: alface: 20 horas; tomate e repolho, 60 horas e cenoura: 72 horas. 
Após, as sementes tratadas foram levadas ao campo e preparadas de acordo com cada tratamento e semeadas.

b) Semeadura

\section{b.1) Semeadura em gel}

o gel utilizado é Viterra ${ }^{(} 2$, da Nepera que é um hidrogel usado no acondicionamento do solo.

A quantidade usada foi de 1\%, sendo que para cada litro de água era necessário $10 \mathrm{~g}$ do gel Laponite para seu prepa ro.

Os lotes de sementes de alface, repolho, tomate e cenoura continham cada um, respectivamente: 200 sementes; 120 sementes; 240 sementes e 200 sementes.

Cada lote de semente foi misturado com 1 litro de gel, sendo o mesmo mexido até as sementes ficarem suspensas no gel.

As misturas foram colocadas em sacos plásticos, com capacidade de 1,5 litro, sendo que as mesmas fluíam para o solo através de um pequeno orifício feito na ponta do saco plástico.

\section{b.2) Semeadura com vermiculita}

A vermiculita foi usada na proporção de 11 para 1, sendo que para cada quilo de semente usou-se 11 quilos de vermiculita no 3. 
A vermiculita foi misturada com água e a esta mistura diluíam-se os lotes de sementes e estas eram então, se meadas manualmente.

\section{b.3) Semeadura convencional}

Sementes secas foram semeadas manualmente.

O repolho foi semeado dia 25/08; O tomate, dia 26/08; a cenoura, dia 30/08 e a alface, dia 31/08.

3.2.3. Delineamento experimental e tratamentos

O experimento foi conduzido em Blocos ao Acaso, com 5 tratamentos e 4 repetições para o tomate, o repolho e a alface e 3 repetições para a cenoura.

As parcelas para o experimento com tomate continham 4 linhas de 40 metros, espaçadas de 1,0 metro, com o total de $330 \mathrm{~m}^{2}$, enquanto que para o repolho foram 4 linhas de 4,0 metros, espaçadas de 0,80 metros, com o total de $264 \mathrm{~m}^{2}$. o repolho foi semeado em covas, sendo a distância entre as mes mas de $0,80 \mathrm{~m}$, total de 20 covas por parcela. Para a alface e cenoura, 4 linhas de 2,0 metros, espaçados de 0,30 metros, totalizando $54,5 \mathrm{~m}^{2}$ para cada experimento.

As áreas totais de cada parcela, foram: tomate, $12 \mathrm{~m}^{2}$; repolho, $9,6 \mathrm{~m}^{2}$; alface, $1,8 \mathrm{~m}^{2}$ e cenoura, $1,8 \mathrm{~m}^{2}$. 
Os tratamentos usados foram:

1. sepente pré-germinada diluída em vermiculita;

2. semente pré-germinada diluída em gel;

3. semente seca diluída em vermiculita;

4. semente seca diluída em gel;

5. semente seca semeada convencionalmente

Os testes para as comparações das médias foram através do teste de Tukey, ao nível de 5\% de probabilidade.

\subsubsection{Avaliação}

A avaliação foi feita através da contagem diária da emergência de seedlings .

Avaliou-se o tempo para 50\% da emergência (T 50) e a porcentagem de emergência diária e total.

\subsection{EXPERIMENTO 2}

As hortaliças utilizadas na $2 a$. fase foram: alface Cv Babá, com 69\% de germinação; cenoura cv Kuroda, com 57\% de germinação; tomate cv Santa Cruz Kada, com 65\% de ger minação e cebola cv Piracicaba precoce, com 78\% de germinação.

Os testes de germinação foram realizados idênticos ao Experimento 1. 


\subsubsection{Tratos culturais}

O controle de plantas daninhas foi feito através

de monda.

O solo foi mantido na capacidade de campo atravês de irrigações diárias.

\subsubsection{Preparo das caixas para semeadura}

a) Caixas com solo

O solo foi o mesmo utilizado no Experimento 1, ou seja, Latossolo Vermelho-Escuro-Orto, série "Luiz de Queiroz".

O solo foi peneirado e acondicionado em caixas de madeira, que tinham as seguintes dimensões: $0,40 \mathrm{~m} \times 0,35 \mathrm{~m}$ $\mathrm{x} 0,10 \mathrm{~m}$.

Com este solo, foram preenchidas doze caixas para cada experimento.

b) Caixas com vermiculita e matéria orgânica

A matéria orgânica utilizada foi esterco de curral curtido, sendo esta peneirada e misturada com vermiculita, na proporção de $1: 1$. Com esta mistura, preencheram-se 6 caixas para cada expeximento. 


\subsubsection{Preparo de sementes e semeadura}

o método utilizado para a pré-germinação das sementes foi semelhante ao experimento anterior.

O tempo para as pré-germinações foi: alface, 24 horas; tomate, 60 horas e cenoura, 72 horas.

As sementes de cebola não germinaram em laboratō rio, mesmo após 96 horas.

Cada lote de sementes continha em média, 414 sementes para alface; 366 sementes para cenoura; 152 sementes para tomate e 216 sementes para cebola. Estas quantidades foram calculadas, tomando-se por base o uso de 0,3 g de sementes por metro linear para alface, cenoura e tomate e $0,5 \mathrm{~g}$ por metro linear para cebola.

O gel foi utilizado na mesma quantidade que o ex perimento anterior. Os lotes de sementes foram misturados a $100 \mathrm{ml}$ do gel e colocados em sacos plásticos com capacidade para 0,5 litro.

Para a mistura vermiculita-matéria orgânica, todos os lotes de sementes foram semeados manualmente.

As semeaduras foram realizadas nos: seguintes dias: alface, 06/04; cenoura, 10/04; tomate: semente seca, 10/04 e semente pré-germinada, 12/4 e cebola, 10/04. 
3.3.4. Delineamento experimental e tratamentos.

O delineamento experimental utilizado foi Ensaio Inteiramente Casualizado, com 3 repetições, para todas as hortaliças utilizadas.

As parcelas para os experimentos continham 4 linhas de 0,40 m, espaçadas de $0,07 \mathrm{~m}$, com um total de $0,084 \mathrm{~m}^{2}$. Os tratamentos usados foram:

1. semente seca + gel + solo;

2. semente pré-germinada + gel + solo;

3. semente seca + solo;

4. semente pré-germinada + solo;

5. semente seca + vermiculita + matéria orgânica;

6. semente prë-germinada + vermiculita + matéria orgânica

o teste para a comparação das médias foi feito através do teste de Tukey, ao nível de 5\% de probabilidade.

\subsubsection{Avaliação}

A avaliação foi feita diariamente, através da contagem de seedlings emergidos.

Avaliou-se o tempo para se obter 50\% de emergência (T50) e a porcentagem de emergência diāria e total. 


\section{RESULTADOS E DISCUSSÃO}

4.1. PARA A FASE DE CAMPO, SEMEADURA NO SOLO

Os resultados dos números de seedlings emergidos, o teste de Tukey para as médias dos nümeros de seeälings emergidos e a porcentagem de emergência diária dos seedlings de al face, estão expressos nas tabelas 1 e 2; para tomate, tabelas 3 e 4 para repolho, tabelas 5 e 6 . As figuras 1, 2 e 3 representam a porcentagem diāria de emergência dos seedlings, respectivamente, para alface, tomate e repolho.

Os resultados referentes à cenoura, não estão sen do apresentados por não terem sido consistentes.

\subsubsection{Alface}

Pela tabela 1 , nota-se que as médias dos nümeros de seedlings emergidos, comparados atravës do teste de Tukey (5\%), não diferiram nos tratamentos de semente seca diluía em gel ou vermiculita e semente pré-germinada diluída em gel ou vermiculita. 
TABELA 1. Número de seedlings emergidos por tratamento e por repetições, de alface cv White Boston, em condições de campo.

\begin{tabular}{|c|c|c|c|c|c|}
\hline \multirow[t]{2}{*}{ TRATAMENTOS } & \multicolumn{4}{|c|}{ REPETIÇÕES } & \multirow{2}{*}{ MÉDIAS } \\
\hline & A & $\mathrm{B}$ & C & $\mathrm{D}$ & \\
\hline semente P.G. + Vermiculita & 158 & 96 & 106 & 64 & $106,0 \mathrm{ab}$ \\
\hline semente seca + Vermiculita & 518 & 49 & 106 & 224 & $224,3 a$ \\
\hline semente P.G. + gel & 201 & 129 & 163 & 161 & $163,5 \mathrm{ab}$ \\
\hline semente seca + gel & 401 & 162 & 181 & 248 & $248,0 a$ \\
\hline testemunha & 45 & 8 & 10 & 21 & $21,0 \mathrm{~b}$ \\
\hline
\end{tabular}

P.G. = pré-ge rminada

D.M.S. $=187,6$

C.V. $=54,54 \%$

Somente nos tratamentos onde foram usadas sementes secas diluídas em gel ou vermiculita, houve diferença com a testemunha, onde foi usado somente semente seca semeada ma nualmente. Nota-se pela tabela 1 , que os tratamentos onde foram usadas sementes diluídas tanto em gel como vermiculita, apresentaram melhores resultados quanto ao nümero de seedlings emergidos.

De acordo com a tabela 2, verifica-se que as maiores porcentagens de emergência total, foram conseguidas pe los tratamentos de sementes secas, diluidas em vermiculita e gel. 
TABELA 2. Porcentagem de emergência de seedlings e porcenta gem total de emergência em campo e o tempo para 50\% de emergência de sementes de alface, cv white Boston, semeadas em 31/08/1982.

\begin{tabular}{|c|c|c|c|c|c|c|c|}
\hline \multirow[b]{2}{*}{ TRATAMENTOS } & \multicolumn{5}{|c|}{ EMERGENCIA } & \multirow{2}{*}{$\begin{array}{c}\text { TOTAL } \\
\%\end{array}$} & \multirow{2}{*}{$\begin{array}{c}\mathrm{T} 50 \\
\text { (dias) }\end{array}$} \\
\hline & $4 / 9$ & $6 / 9$ & $8 / 9$ & $10 / 9$ & $12 / 9$ & & \\
\hline sem. P.G. + Verm. & 9,37 & $1.4,58$ & 2,47 & 0,85 & 0,33 & 27,60 & - \\
\hline sem. seca + Verm. & 25,85 & 27,54 & 3,65 & 1,11 & 0,26 & 58,41 & 6 \\
\hline sem. P.G. + gel & 9,70 & 30,01 & 1,76 & 0,65 & 0,46 & 42,58 & - \\
\hline sem. seca + gel & 25,13 & 31,38 & 8,85 & 3,65 & 0 & 69,01 & 6 \\
\hline testemmina & 0 & 2,34 & 2,30 & 0,19 & 0,85 & 5,68 & - \\
\hline
\end{tabular}

O tempo para 50\% de emergência de seedlings (T50), foi atingido pelos tratamentos de sementes secas diluidas em gel ou vermiculita, em 6 dias. Os demais tratamentos não atingiram 50\% de emergência (dentro do período: observado) . 


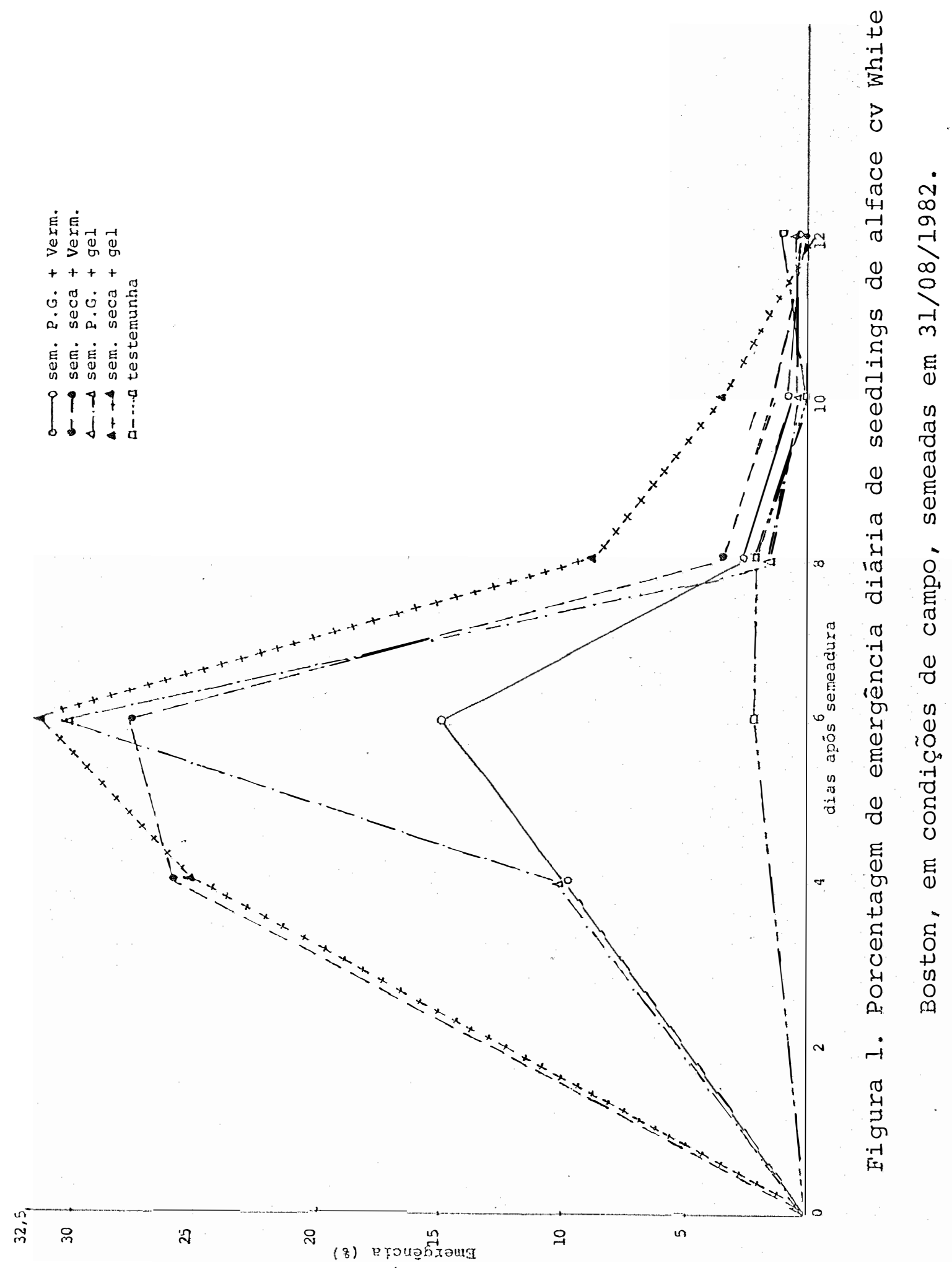




\subsubsection{Tomate}

TABELA 3. Quantidade de seedlings emergidos por tratamento e por repetição, de tomate cv. Santa Cruz Kada, em con dições de campo.

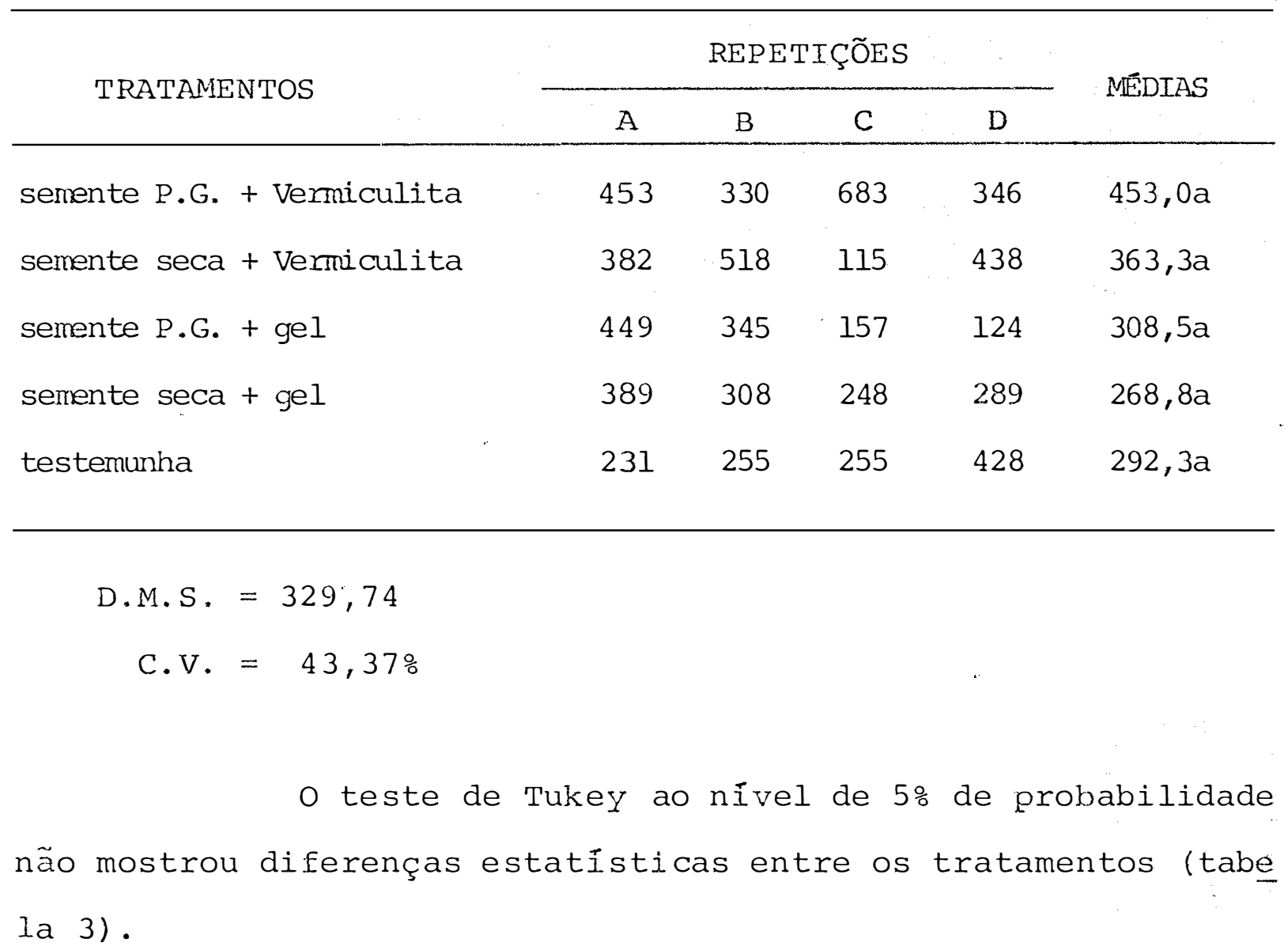


TABELA 4. Porcentagem de emergência diāria de seedlings, porcentagem total de emergência em campo e o tempo para 50\% de emergência (T50), para tomate cv santa Cruz Kada, semeado em $26 / 08 / 1982$.

\begin{tabular}{|c|c|c|c|c|c|c|}
\hline \multirow[b]{2}{*}{ TRATAMENTOS } & \multicolumn{4}{|c|}{ PORCENTAGEM EE EMERGENCIA DIARLA } & \multirow{2}{*}{$\begin{array}{c}\text { TOTAL } \\
\quad \%\end{array}$} & \multirow{2}{*}{$\begin{array}{r}\mathrm{T} 50 \\
\text { (dias }\end{array}$} \\
\hline & $1 / 9$ & $3 / 9$ & $6 / 9$ & $8 / 9$ & & \\
\hline sem. P.G. + Verm. & 7,67 & 19,31 & 8,33 & 4,01 & 39,32 & - \\
\hline sem. seca + Verm. & 12,07 & 12,37 & 5,84 & 1,26 & 31,54 & - \\
\hline sem. P.G. + gel & 0,67 & 11,76 & 8,81 & 2,08 & 23,32 & - \\
\hline sern. seca + gel & 2,47 & 16,32 & 7,73 & 0,26 & 26,78 & - \\
\hline testemunha & 1,76 & 14,02 & 7,49 & 2,11 & 25,38 & - \\
\hline
\end{tabular}

O tempo para 50\% de emergência de seedlings (T50) naõ foi atingido em nenhum dos tratamentos. 


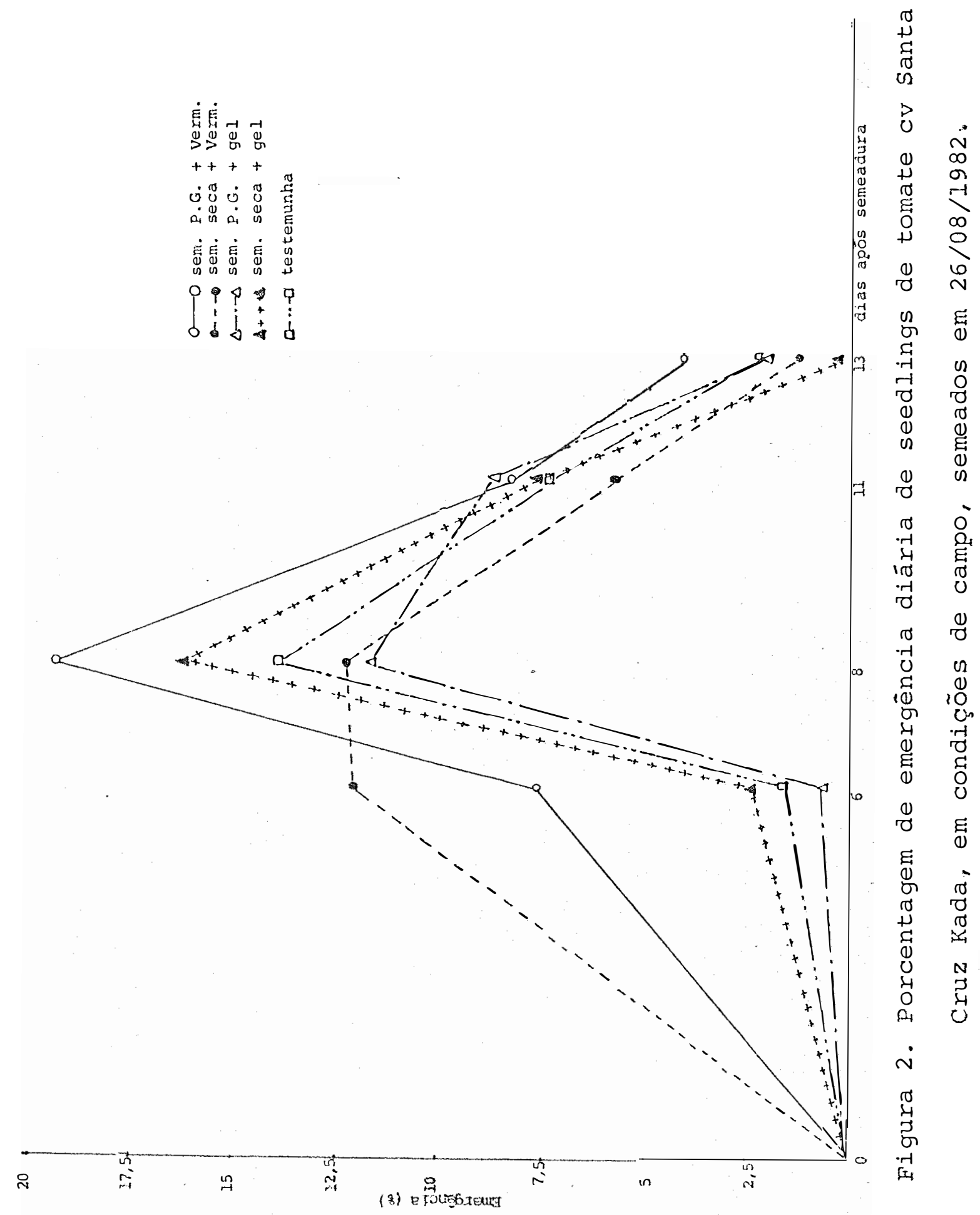




\subsubsection{Repolho}

TABELA 5. Quantidade de seedlings emergidos, por tratamento e por repetições, de repolho CV híbrido Natsumaki Riso.

\begin{tabular}{|c|c|c|c|c|c|}
\hline \multirow{2}{*}{ TRATAMENTOS } & \multicolumn{4}{|c|}{ REPETIÇÕES } & \multirow{2}{*}{ MEDIA } \\
\hline & A & B & $\mathrm{C}$ & $\mathrm{D}$ & \\
\hline sem. P.G. + Verm. & 64 & 27 & 34 & 49 & $43,5 \mathrm{~b}$ \\
\hline sem. seca + Verm. & 59 & 70 & 48 & 41 & $54,5 \mathrm{~b}$ \\
\hline sem. P.G. + gel & 99 & 87 & 79 & 79 & $86,0 a$ \\
\hline sem. seca + gel & 79 & 107 & 81 & 84 & $87,8 \mathrm{a}$ \\
\hline testemunha & 63 & 45 & 58 & 58 & $56,0 \mathrm{~b}$ \\
\hline
\end{tabular}

D.M.S. $=27,34$

C.V. $=18,48 \%$

A comparação das médias pelo teste de Tukey ao nível de 5ㅁ de probabilidade, mostram que os melhores tratamen tos foram os que usaram as sementes diluídas em gel para a semeadura. 
TABELA 6. Porcentagem de emergência diäria de seedlings, porcentagem total de emergência em campo e o tempo para 50\% de emergência (T50) de repolho cV Natsumaki Riso. Semeadura realizada em 25/08/1982.

\begin{tabular}{|c|c|c|c|c|c|c|}
\hline \multirow[b]{2}{*}{ TRATAMENTOS } & $\frac{8}{8}$ & EMERGÊENCIA & DI $\bar{A} R I A$ & 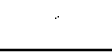 & \multirow{2}{*}{$\begin{array}{c}\text { TOTAL } \\
\%\end{array}$} & \multirow{2}{*}{$\begin{array}{c}\text { T50 } \\
\text { (dias) }\end{array}$} \\
\hline & $1 / 9$ & $3 / 9$ & $6 / 9$ & $8 / 9$ & & \\
\hline sem. P.G. + Verm. & 34,44 & 8,44 & 3,70 & 1,75 & 48,33 & - \\
\hline sem. seca + Verm. & 49,78 & 7,22 & 1,89 & 1,67 & 60,56 & 7 \\
\hline sem. P.G. + gel & 64,22 & 25,00 & 3,00 & 3,33 & 95,55 & 7 \\
\hline sem. seca + gel & 46,89 & 31,55 & 13,11 & 6,11 & 97,66 & 9 \\
\hline testemumha & 44,67 & 15,00 & 1,67 & 0,89 & 62,23 & 9 \\
\hline
\end{tabular}

Com base nos resultados apresentados na tabela 6 , verifica-se que os tratamentos que melhor porcentagem de emergência apresentaram foram os de sementes pré-germinadas e se mentes secas diluídas em gel, obtendo excelente porcentagem de emergência total.

Quanto ao tempo para atingir 50\% de emergência, sô näo foi conseguido pelo tratamento de semente pré-germinada, diluída em vermiculita. 


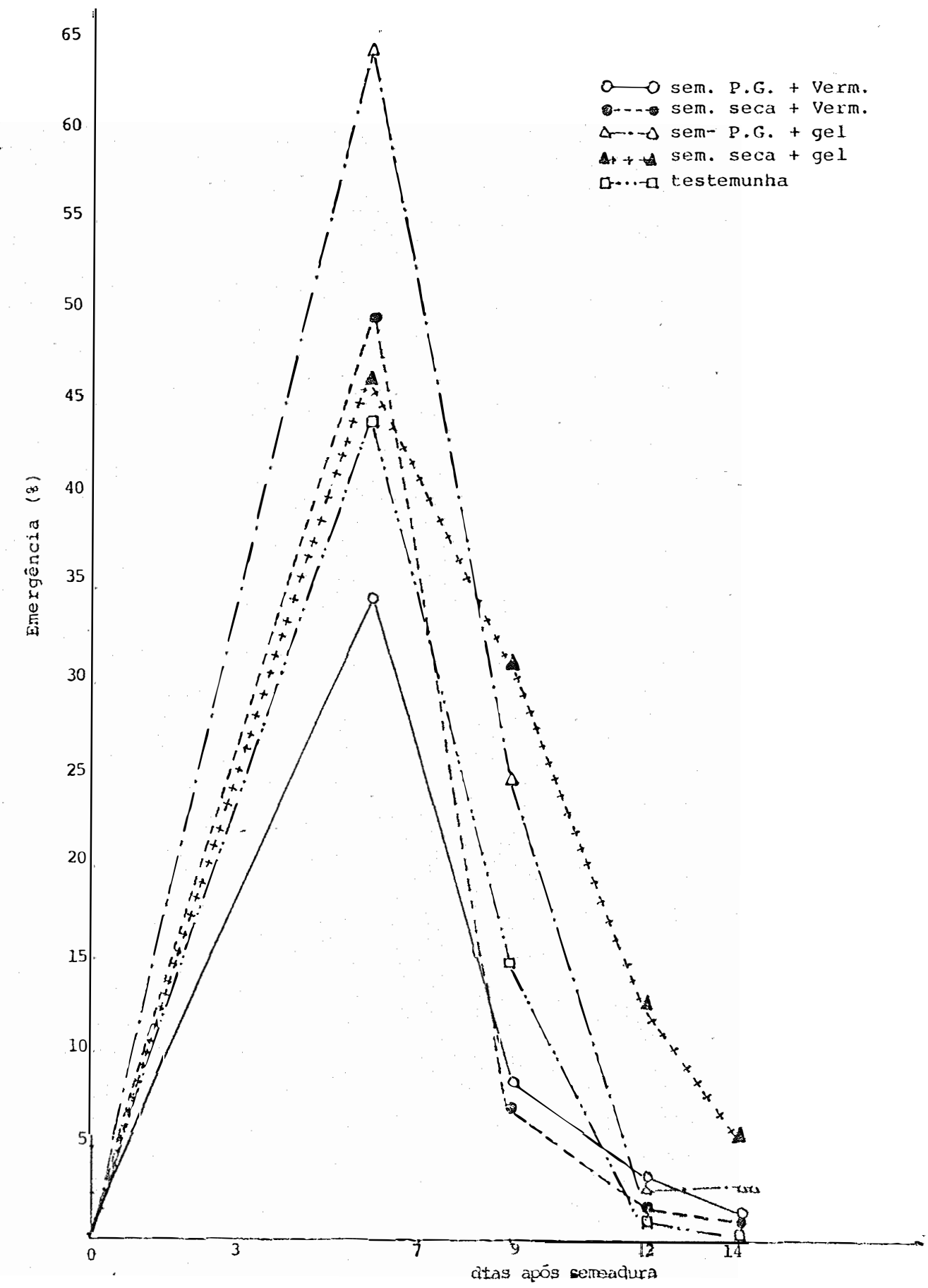

Figura 3. Porcentagem de emergência diária de seedlings de repolho cv Natsumaki Riso, em condiçöes de campo. Semeadura em 25/08/1982. 


\subsubsection{Cenoura}

Os dados sobre emergência de sementes de cenoura não estão sendo apresentados por não serem consistentes, isto devido a perdas que houve no experimento, devido à seca que houve na época (tabela 15 do apêndice), e pela irrigação não ter sido suficiente para suprir a quantidade de água exigida pela cultura.

\subsection{PARA A FASE DE CAMPO, SEMEADURA EM CAIXAS}

Os resultados dos nümeros de seedlings emergidos, o teste de Tukey para as médias da quantidade de seedlings emergidos e a porcentagem de emergência diāria total e T50 dos seedlings de alface, estão expressos nas tabelaș 7 e 8 ; para tornate, tabelas 9 e 10; para cenoura, tabelas 11 e 12 e para cebola, tabelas 13 e 14 . As figuras 4, 5, 6 e 7, representarn a porcentagem de emergência diária dos seedlings, respectivamente, para: alface, tomate, cenoura e cebola.

4.2.1. Alface 
TABEIA 7. Quantidade de seedlings emergidos, por tratamentos e por repetiç̃ões, de alface cv Babá.

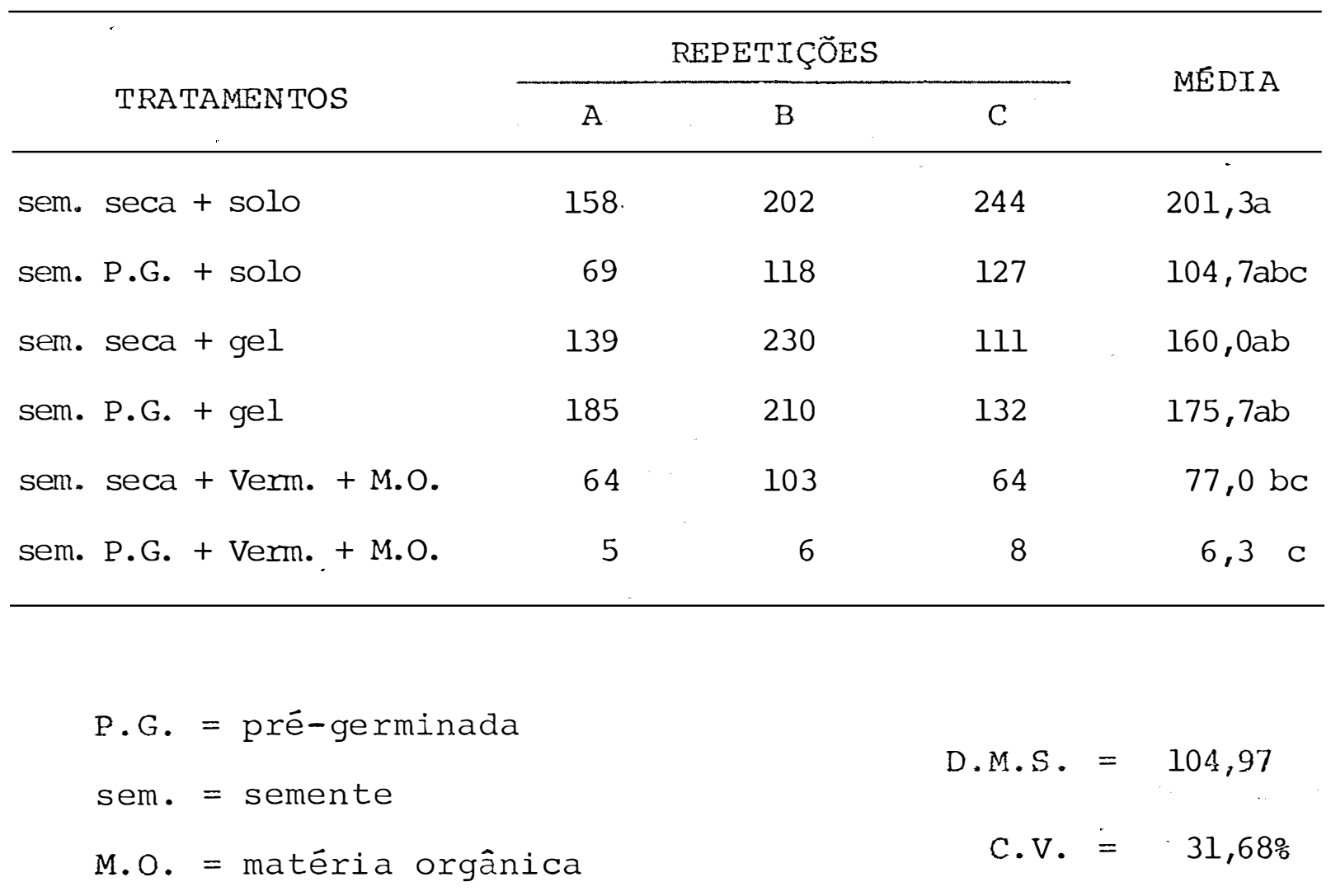

As medias da quantidade de seedlings emergidos atxavés do teste de Tukey ao nível de 5\% de probabilidade (tabela 7) nos mostram que os melhores tratamentos fcram os que não usaram a vermiculita e a matéria orgânica como um substrato. 
TABElA 8. Porcentagem diária de emergência de seedlings, porcentagem total de emergência em campo e o tempo para se obter 50\% de emergência de sementes de alface cv Babá, sẹneadas em 06/04/1984.

\begin{tabular}{|c|c|c|c|c|c|c|c|c|c|}
\hline & \multirow{2}{*}{ TRATAMENTOS } & \multicolumn{3}{|c|}{ \% EMERGÊNCIA } & \multicolumn{3}{|c|}{ DIĀRIA } & \multirow{2}{*}{$\begin{array}{c}\text { TOPAI, } \\
\text { \% }\end{array}$} & \multirow{2}{*}{$\begin{array}{r}\mathrm{T} 50 \\
\text { dias } \\
\end{array}$} \\
\hline & & $9 / 4$ & $10 / 4$ & $11 / 4$ & $12 / 4$ & $16 / 4$ & $18 / 4$ & & \\
\hline sem. & seca + solo & 44,88 & 22,39 & 0,95 & 0,80 & 0,95 & 0,25 & 70,42 & 4 \\
\hline sem. & P.G. + solo & 30,68 & 3,39 & 1,40 & 0,70 & 0,25 & 0,25 & 36,77 & - \\
\hline sem. & seca + gel & 32,29 & 19,35 & 2,69 & 0,95 & 0,45 & 0,25 & 56,14 & 4 \\
\hline sem. & P.G. + gel & 47,13 & 9,69 & 2,20 & 1,75 & 0,59 & 1,10 & 61,65 & 4 \\
\hline sem. & seca + Verm. + M.O: & 7,35 & 16,68 & 0,45 & 0,59 & 1,05 & 0,70 & 26,91 & - \\
\hline sem. & P.G. + Verm. + M.O. & 1,40 & 0,11 & 0 & 0,11 & 0,45 & 0,11 & 2,17 & - \\
\hline
\end{tabular}

Analisando-se a tabela 8, verifica-se que os tratamentos que usaram gel como diluente e o tratamento que usou semente seca + solo, foram os que conseguiram atingir. o tempo para se obter. 50\% de emergência, podendo, assim, dizer que o estabelecimento do stand foi atingido em 4 dias por estes tratamentos. Os demais tratamentos não conseguiram estabelecer 0 stand: . 


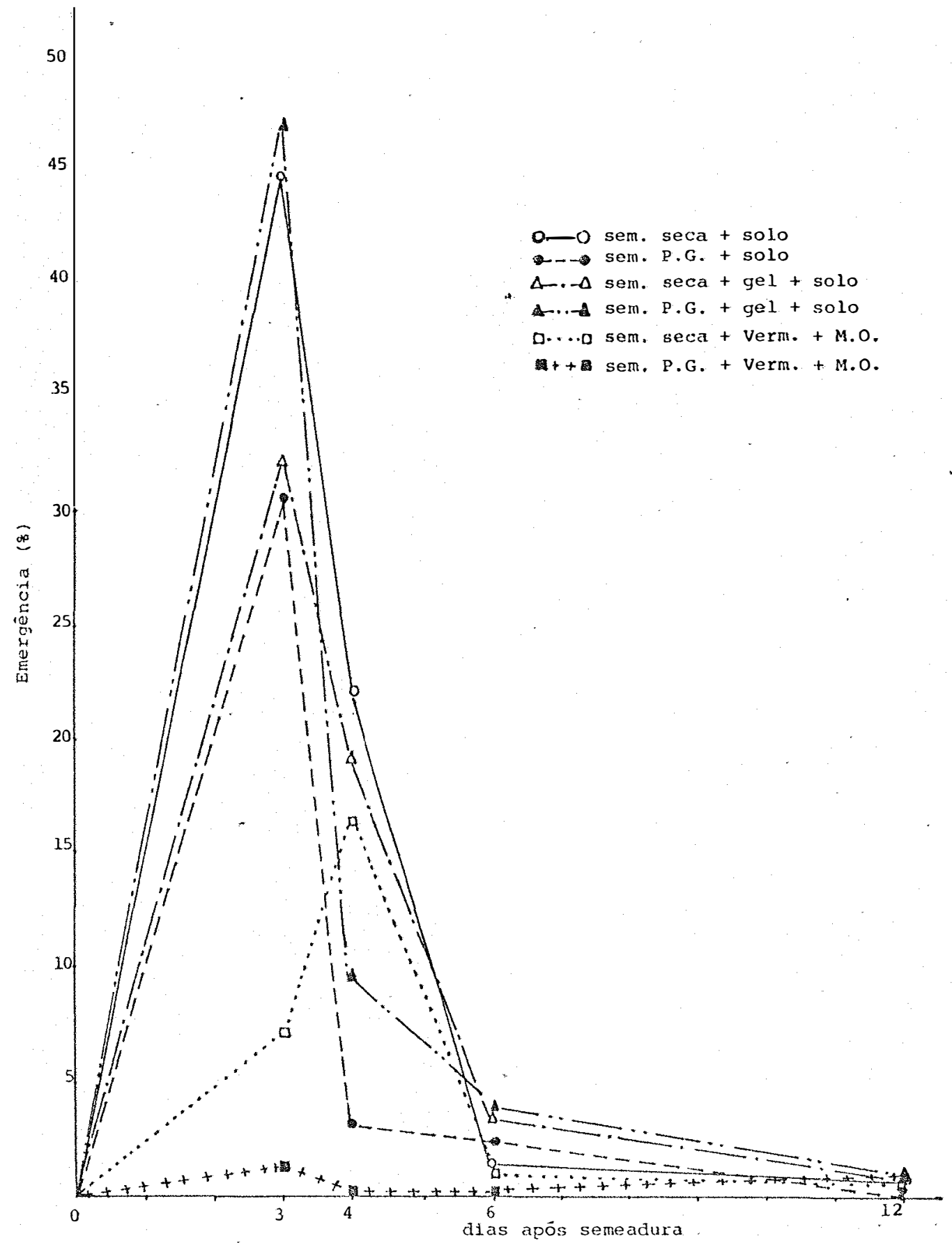

Figura 4. Porcentagem de emergência diária de seedlings de alface cv Babá, semeada em 06/04/1984. 


\subsubsection{Tomate}

TABELA 9. Quantidade de seedlings emergidos, por tratamentos e por repetições, de tomate cv Santa Cruz Kada.

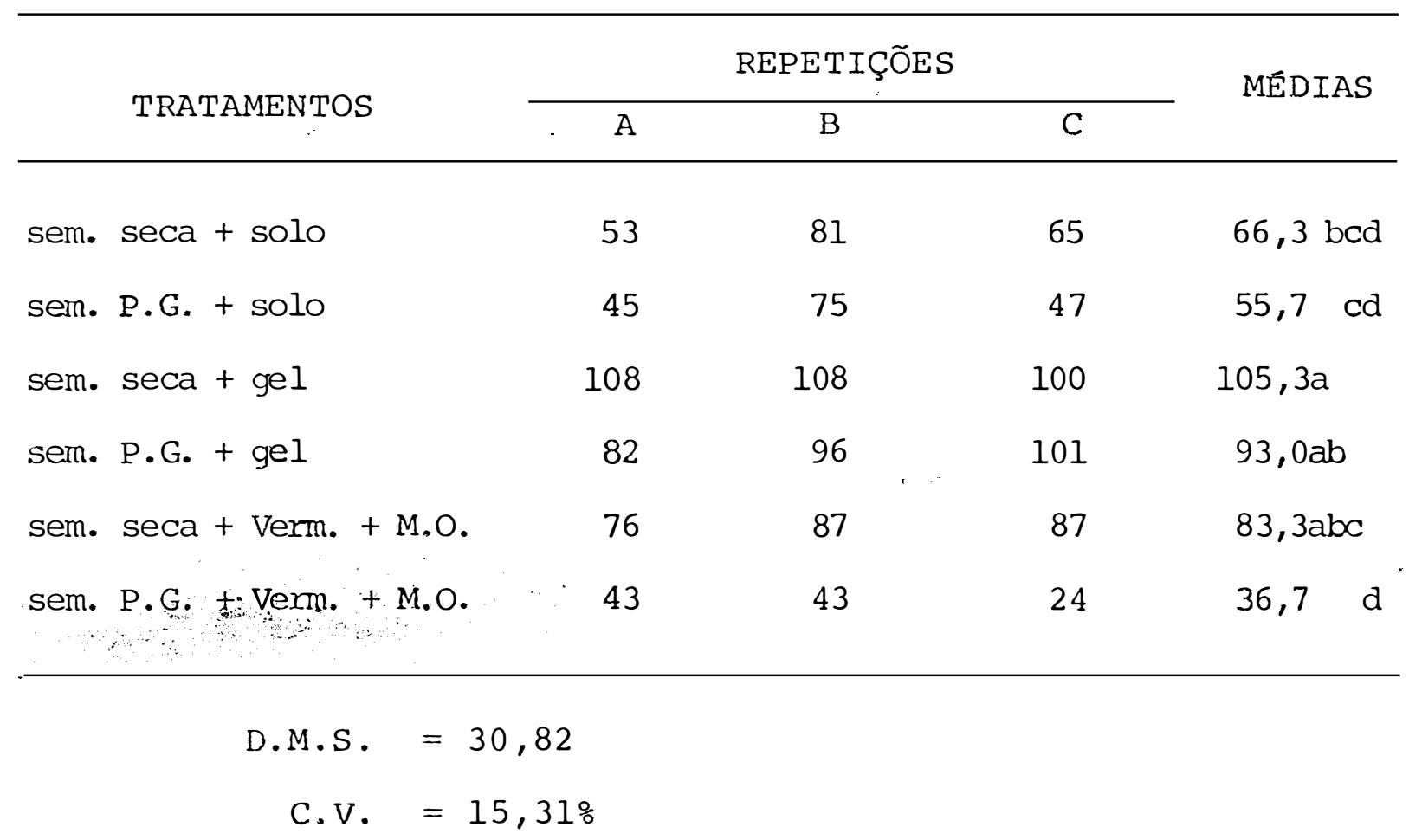

Os tratamentos que apresentavam melhores respostas quanto aos números de seedlings emergidos para tomate, foram aqueles cujas sementes foram diluidas em gel, tal como encontrado por GRAY et ali.i (1979) e o tratamento de sementes se cas semeadas no substrato: vermiculita + matēria orgânica, tam bém apresentou boa resposta quanto ao nümero de seedlings emer gidos (tabela 9). 


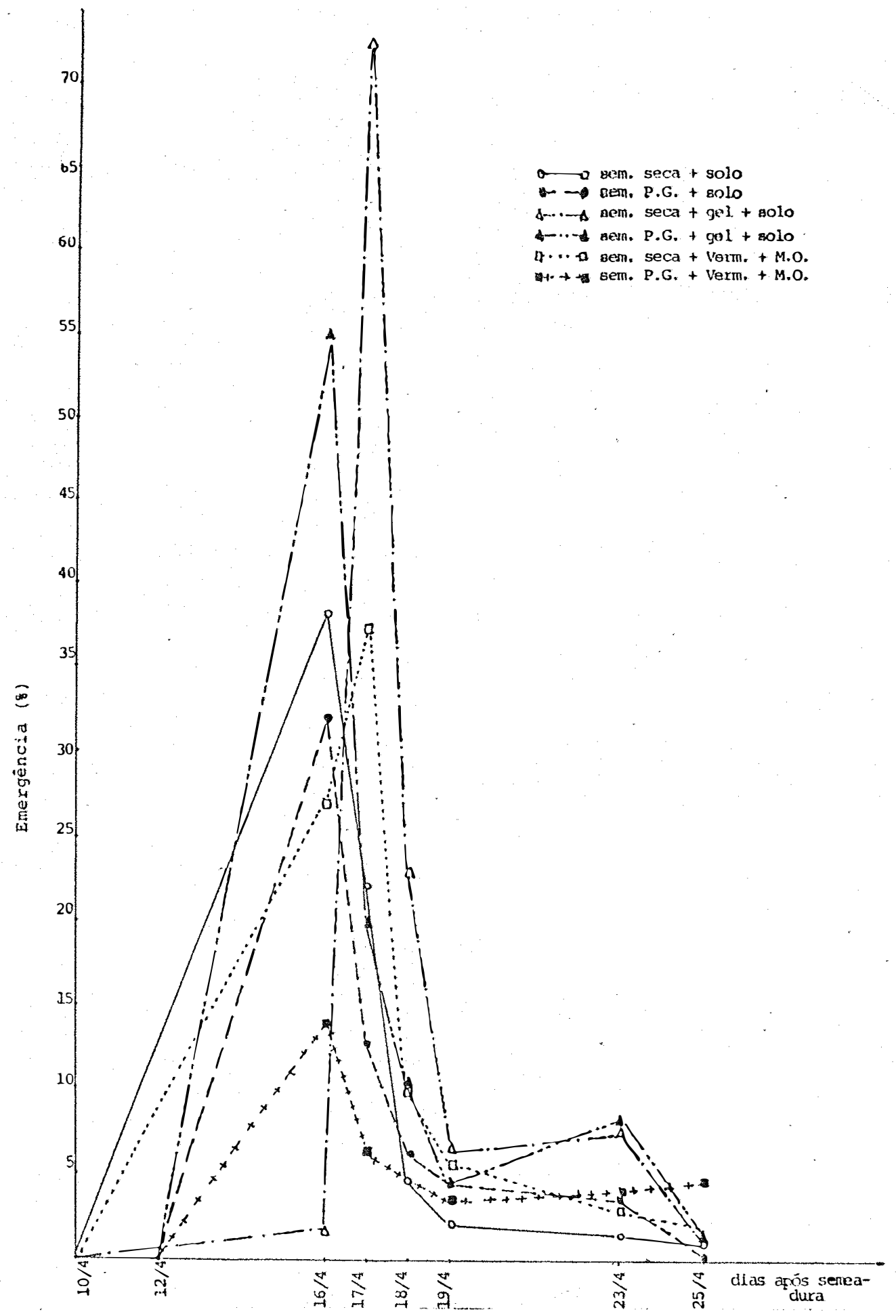

Figura 5. Porcentagem de emergência diāria de seediings de to mate CV Santa Cruz Kada. Semeadura de sementes secas: 10/04/1984 e de sementes pré-germinadas: 12/04/84. 


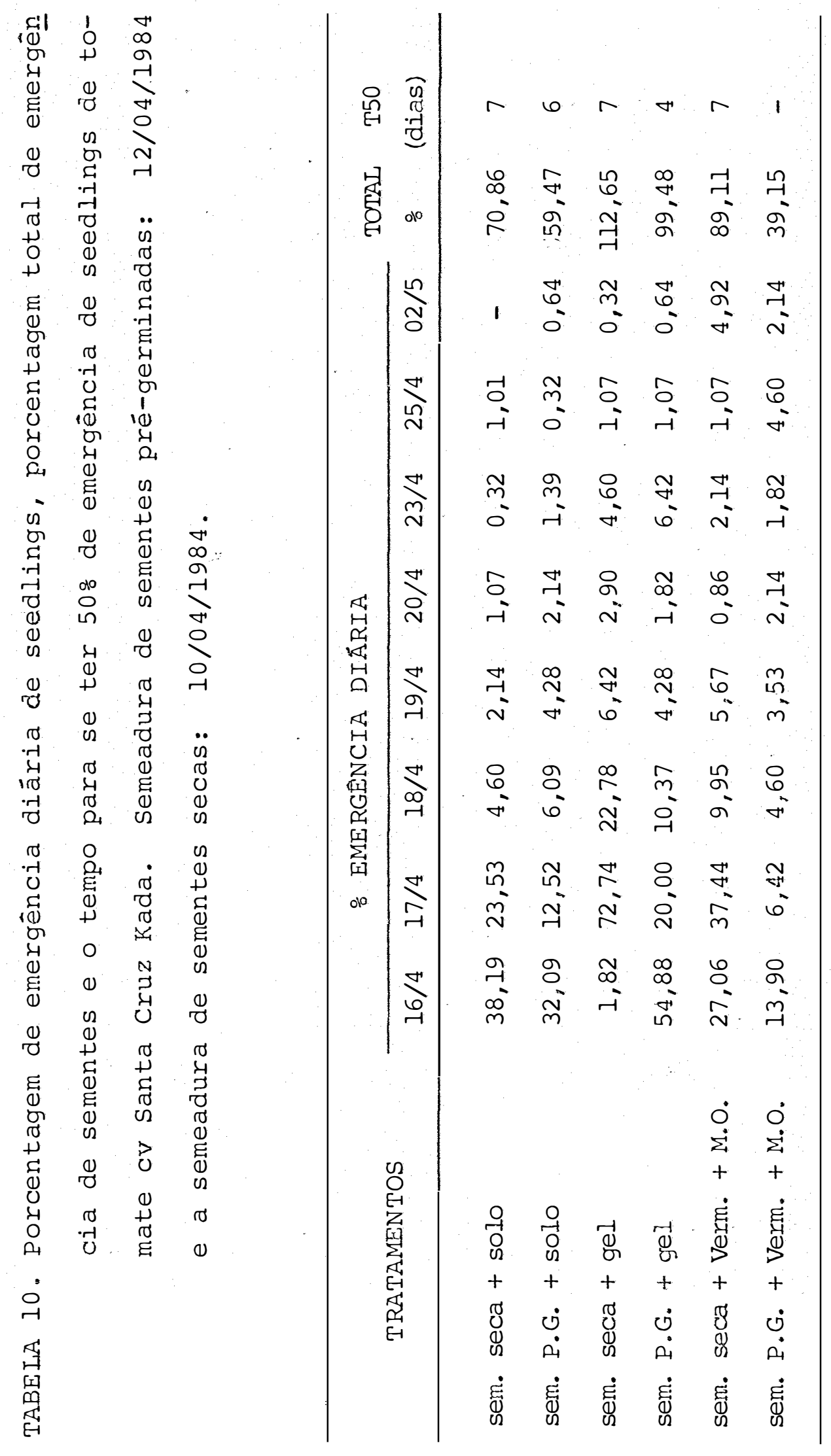


Pela tabela 10 , verifica-se que somente o trata mento com semente pré-germinada semeada no substrato: vermiculita + matéria orgânica, não atingiu o tempo para 50\% de emergência. Analisando a tabela, verifica-se ainda, que o tratamento que levou menos tempo para atingir o T50, foi aquele onde as sementes foram prë-germinadas, semeadas com gel, o que é concordante com WOLFE e SIMS (1982).

\subsubsection{Cenoura}

TABELA 11. Quantidade de seedlings emergidos por tratamentos e por repetições de sementes de cenoura cV Kuroda.

\begin{tabular}{|c|c|c|c|c|c|}
\hline & \multirow{2}{*}{ TRATAMENTOS } & \multicolumn{3}{|c|}{ REPETIÇÕES } & \multirow{2}{*}{ MEDIAS } \\
\hline & & $\mathrm{A}$ & $\mathrm{B}$ & C & \\
\hline sem. & seca + solo & 105 & 152 & 120 & $125,7 \mathrm{ab}$ \\
\hline sem. & P.G. + solo & 96 & 111 & 88 & $98,3 \mathrm{~b}$ \\
\hline sem. & seca + gel & 78 & 130 & 99 & $102,3 \mathrm{~b}$ \\
\hline sem. & P.G. + gel & 16 & 43 & 26 & $28,3 \quad$ \\
\hline sem. & seca + Verm. + M.O. & 166 & 167 & 142 & $158,3 a$ \\
\hline sem. & P.G. + Verm. + M.O. & 71 & 81 & 85 & $79,0 \mathrm{~b}$ \\
\hline
\end{tabular}

$$
\begin{aligned}
\text { D.M.S. } & =104,97 \\
\text { C.V. } & =31,67 \%
\end{aligned}
$$


Verificando-se a tabela 11 , pode-se ver que as respostas foram bem variadas quanto aos tratamentos, sendo que os tratamentos que se destacaram foram os de sementes secas, semeadas tanto no solo como no substrato: vermiculita + matéria orgânica.

TABEIıA 12. Porcentagem de emergência diāria de seedlings, porcentagem total de emergência de seedlings e o tempo para se atingir $50 \%$ de emergência de sementes de ce noura CV Kuroda. Semeadura: 10/04/1984.

\begin{tabular}{|c|c|c|c|c|c|c|c|c|c|}
\hline \multirow{2}{*}{ TRATAMENTOS } & \multicolumn{7}{|c|}{ \% EMERGENCIA DIARTA } & \multirow{2}{*}{\multicolumn{2}{|c|}{$\begin{array}{l}\text { TORAL T50 } \\
\quad \% \text { (dias) }\end{array}$}} \\
\hline & $16 / 4$ & $17 / 4$ & $18 / 4$ & $19 / 4$ & $20 / 4$ & $25 / 4$ & $02 / 5$ & & \\
\hline sem. seca + solo & 0,62 & 20,13 & 22,19 & 13,42 & 1,77 & 1,29 & 0,82 & 60,24 & 4.9 \\
\hline sem. P.G. + solo & 5,42 & 7,19 & 13,76 & 11,84 & 4,79 & 2,53 & 1,58 & $47,1.1$ & $1-$ \\
\hline sem. seca + gel & - & 1,44 & 20,47 & 21,57 & 2,73 & 1,58 & 1,25 & 49,04 & $4-$ \\
\hline sem. P.G. + gel & 0,14 & 4,94 & 3,98 & 2,54 & 0,96 & 0,85 & 0,14 & 13,55 & $5-$ \\
\hline sem. secarVerm. +M.O. & 1,29 & 30,05 & 29,38 & 9,73 & 2,73 & 2,39 & 0,28 & 75,85 & 58 \\
\hline sem.. . G. +Verm. +M. O. & 6,57 & 9,25 & 10,55 & 6,37 & 2,78 & 1,43 & 0,91 & 37,86 & $6-$ \\
\hline
\end{tabular}

Os ünicos tratamentos onde foram estabelecidos os stands, foram os de semente seca + solo e o de semente seca semeada no substrato: vermiculita + matëria orgânica (tabela 12 ). 


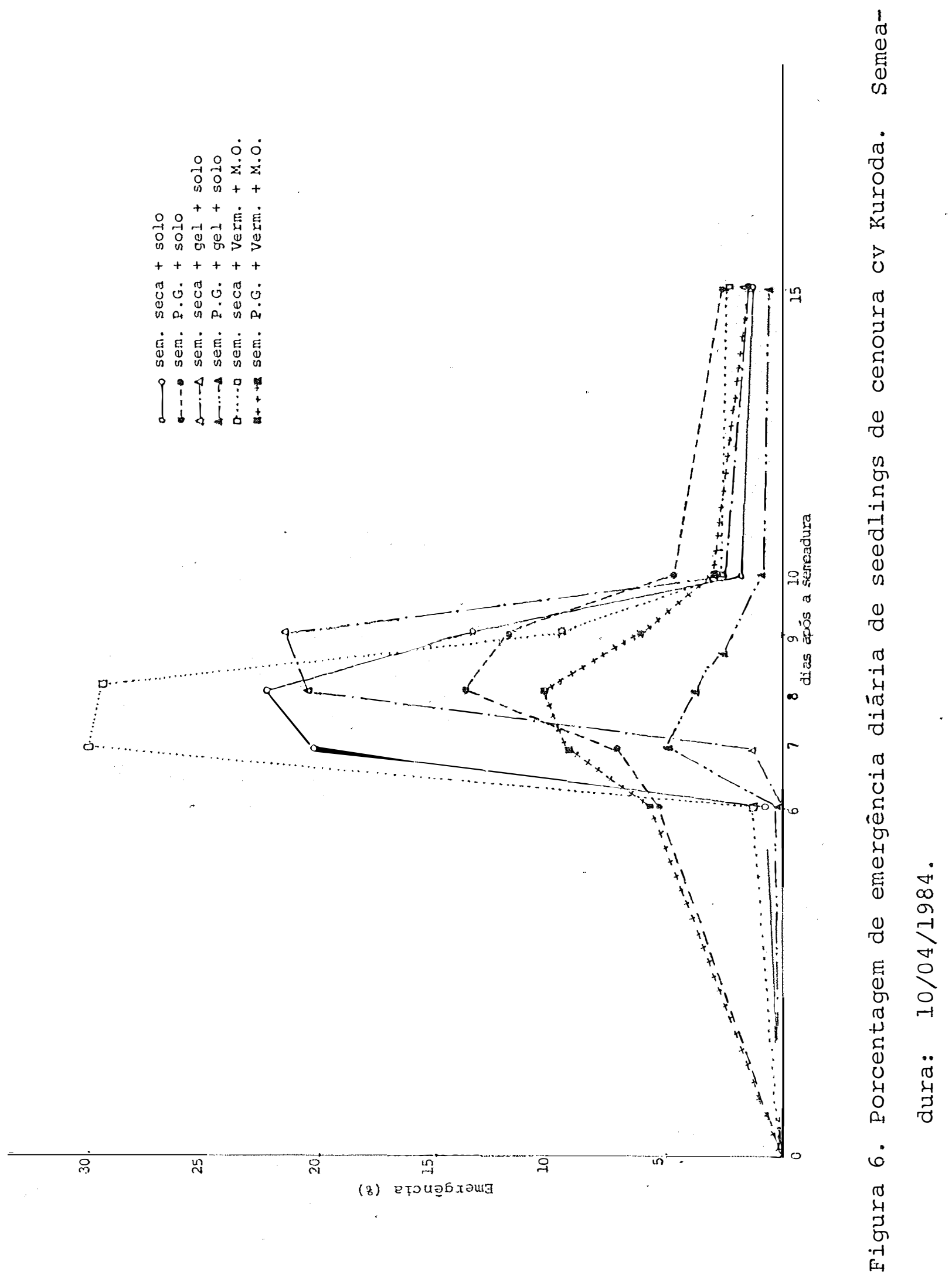




\subsubsection{Cebola}

Como nota apresentada em materiais e métodos, so mente serão apresentados os dados referentes a sementes secas, devido às sementes não terem sido pré-germinadas em laboratório, mesmo apōs 96 horas.

TABELA 13. Quantidade de seedlings emergidos por tratamento e por repetições de cebola cv Piracicaba Precoce.

\begin{tabular}{lcccc}
\hline \multirow{2}{*}{ TRATANENTOS } & \multicolumn{3}{c}{ REPETIÇÕES } & MEDIAS \\
\cline { 2 - 4 } & A & B & C & \\
\hline sem. seca + solo & 75 & 79 & 84 & $79,3 a$ \\
sem. seca + gel & 95 & 83 & 65 & $81,0 \mathrm{a}$ \\
sem. seca + Vexm. + M. O. & 42 & 53 & 49 & $48,0 \mathrm{~b}$ \\
\hline
\end{tabular}

D.M.S. $=24,18$

C.V. $=13,90 \%$

De acordo com o teste de Tukey ao nível de 5응 de probabilidade (tabela 13), os melhores tratamentos foram os de sementes secas, diluídas em gel e semeadas diretamente no solo. 


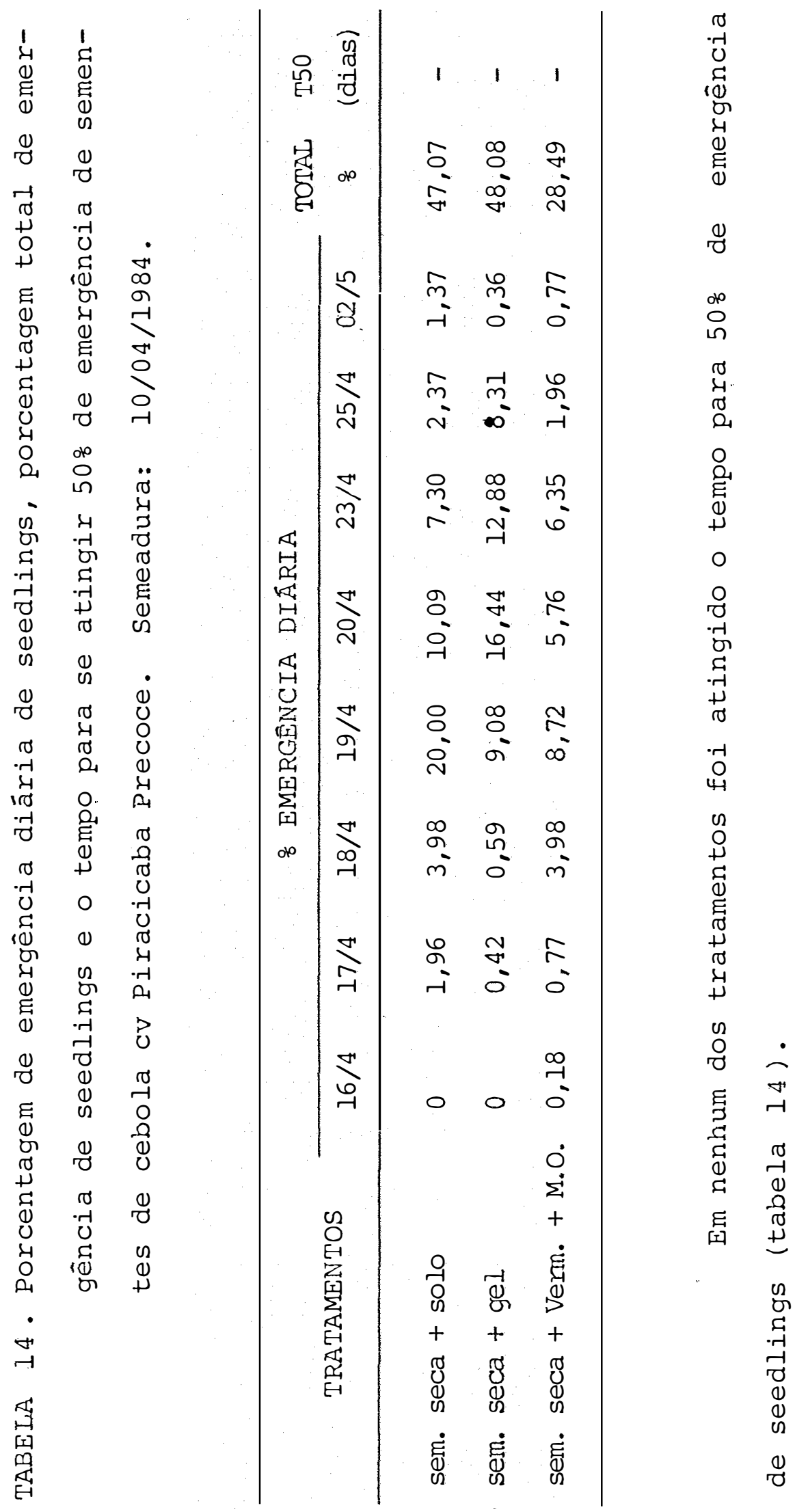




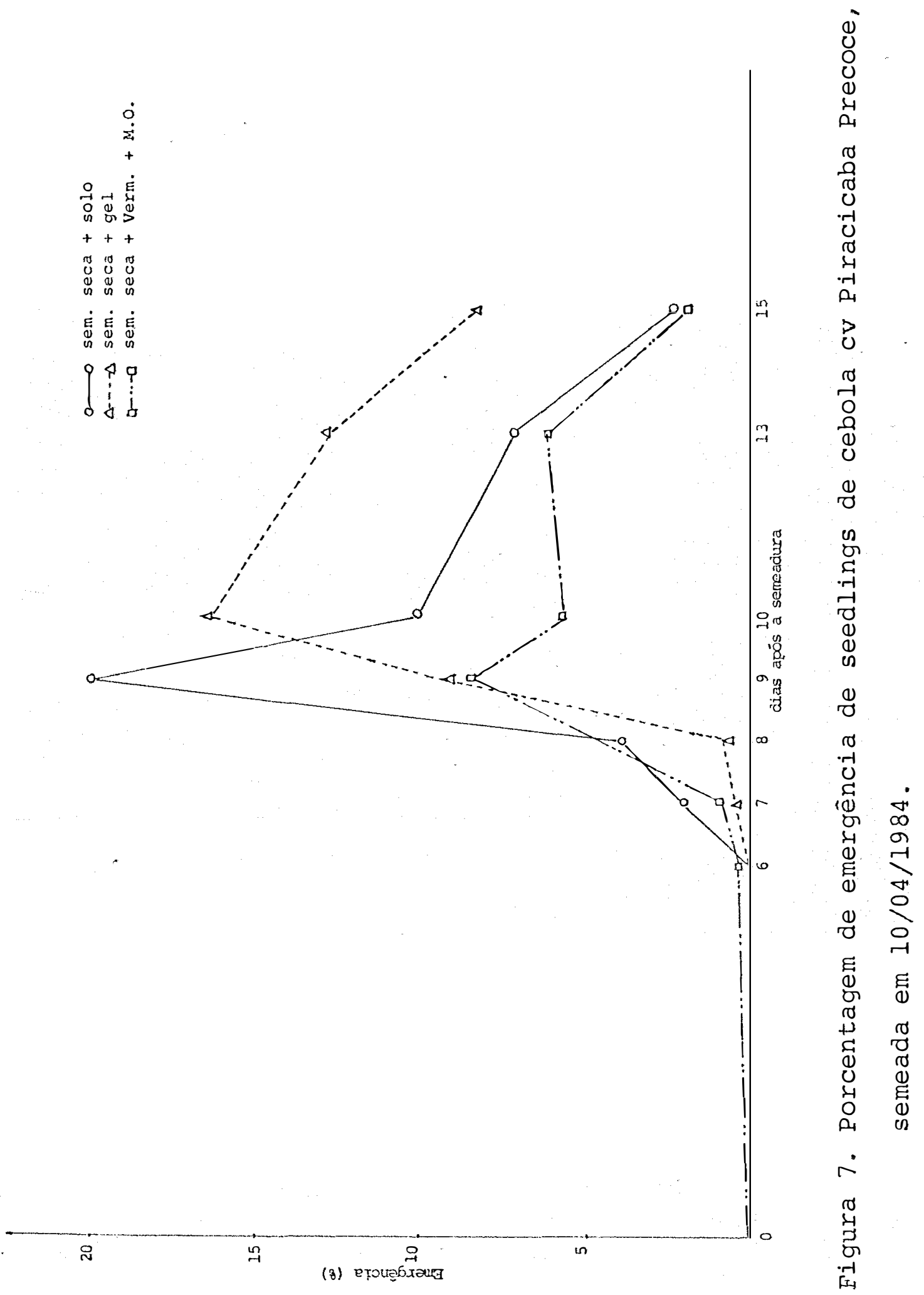




\subsection{CONSIDERAÇÕES GERAIS}

Os experimentos da 2a. época apresentaram melhores respostas quanto à emergência de seedlings, como verificado pelos coeficientes de variações; isto se deve talvez, a dois fatores: 10) água: na 2a. época o solo sempre permaneceu na capacidade de campo, com regas diārias, o mesmo não ocorrendo na la. época, onde o fornecimento de água foi através de irrigação por aspersão, sendo o fornecimento de água não suficiente para suprir as necessidades exigidas pelas culturas; 2\%) plantas daninhas: 020 experimento sendo, em área menor, foi fácil de controlar as plantas daninhas através de monda, porêm, no 19 experimento houve uma reinfestação de tiririca, não sendo fácil seu controle nas linhas de semeadura e estas podem ter competido com as culturas, resultando assim, numa menor emergência de seedlings.

No 29 experimento nota-se que para alface è tomate e cenoura (quando se comparam os tratamentos que usaram subs tratos), observa-se que os tratamentos que usaram sementes prẹ germinadas semeadas no substracio vermiculita - matéria orgânica, deram os piores resultados. Possivelmente isto se deva ao uso de esterco de curral, como matêria orgânica, ter dado condições para o crescimento de fungos e bactérias do solo afetan do as sementes.

Para as hortaliças alface cV White Boston, repo- 
lho cv Natsumaki Riso, alface cv Babä e tomate cv santa. Cruz Kada (na 2a. ëpoca), as emergências dos seedlings apresentaram respostas satisfatórias nos tratamentos onde o gel foi usado, o que é concordante com GRAY (1976), GRAY (1978a e b) e GRISMS HAM (1981) .

Analisando-se $0 \mathrm{~T}_{50}$, ou seja, tempo para se obter $50 \%$ de emergência de seedlings, observa-se que mesmo nos trata mentos que atingiram-no, estas diferenças não foram significativas, pois, GRAY et alii (1979) e GRAY (1981) têm encontrado adiantamento de emergência, usando-se sementes pré-germinadas ou secas, diluídas em gel, a baixas temperaturas.

Apesar de não ter sido encontrada uma maneira efi ciente para medir qual o melhor processo de semeadura, foi observado que os processos onde as sementes foram diluídas .. em gel e em vermiculita, foram os mais práticos de serem realizados, tanto pelo manejo das sementes, como pelo tempo de semeadura que foi bem menor do que os de sementes secas não diluídas. 


\section{CONCLUSÕES}

Nas condições em que este trabalho foi realizado e, tendo-se em conta os resultados obtidos, podem ser estabele cidas as seguintes conclusões:

1. De uma maneira geral, os tratamentos cujas sementes foram diluídas em gel(semeadura líquida) ou vermiculita, apresen taram melhores resultados quanto à quantidade de seedlings emergidos;

2. O estabelecimento do stand foi atingido nos seguintes experimentos: a) repolho cv Natsumaki Riso, sö não houve estabelecimento do stand nos tratamentos onde foram usa das as sementes pré-germinadas diluídas em vermiculita ; b) alface cv Babá, semeada em abril de 1984, atingiram o stand os tratamentos que usaram sementes secas e prë-ger minadas diluidas em gel e onde a semente seca foi semeada diretamente no solo; c) tomate cv Santa Cruz Kada (semea dura: abril de 1984) só não houve estabelecimento da cul 
tura onde foram usadas sementes pré-germinadas, semeadas no substrato vermiculita - matéria orgânica; d) cenoura cV Kuroda (semeadura em abril de 1984), foi atingido pelos tratamentos de sementes secas + matéria orgânica;

3. A adição da matéria orgânica à vermiculita foi prejudicial para as sementes de alface, tomate e cebola e foi be néfico para as sementes de cenoura, cv. Kuroda.

4. A pré-germinação foi tão eficiente quanto à semente seca em relação à emergência total, para a semeadura com gel ou vermiculita, desde que não haja matéria orgânica;

5. A diluição em gel ou vermiculita facilita a semeadura. De um modo geral, a semeadura em gel ou vermiculita foi eficiente para a semeadura das hortaliças estudadas, além.. de ser mais prätica;

6. Um bom stand sö é estabelecido se houver um ótimo manejo de āgua e um ötimo manejo de plantas daninhas, fatores que interferem diretamente na semeadura. 


\section{LITERATURA CITADA}

BAtAL, K.M.; S.R. GHATE e S.C. PHATAK, 1983. Responses of fluid drilling broccoli to chemical additives. Annals of Applied Biology. Cambridge, 102 (Supplement):120-121.

BIDDINGTON, N.L.; T.H. THOMAS e A.J. WHITLOCK, 1975. Celery yield increased by sowing germinated seeds. HortScience . Michigan, 10:620-621.

BOODLEY, J.W. e R. SHELDRAKE JR., 1969. Carnation production in vermiculite amended media. Journal of Horticultural Science. London, 94:512-514.

BRYAN, H.H.; W.M. STALL; D. GRAY E N.S. RICHMOND, 1978. Fluid drilling of pre germinated seeds for vegetable gardening . Proceeding of the Florida state Horticultural Society. Flo rida, 91: 88-90. 
BUSSEL, W.T. e D. GRAY, 1976. Effects of presowing seeds treatments and temperatures on tomato seed germination and seedling emergence. Scientia Horticulturae. Amsterdam, $\underline{5}$ : $101-109$.

COELHO, R.G.; L.A.B. de CASTRO; M.T. LIBERAL; R.C. COELHO; O H.T. LIBERAL e A.L. PEREIRA, 1973. Influência do tamanho da semente de quiabo (Hibiscus esculentus L.) em sua performance. Revista de Olericultura. Viçosa, MG, 1.3:83-84.

CURRAH, I.E.; D. GRAY e T.H. THOMAS, 1974. The sowing of ger minating vegetable seeds using a fluid drill. Annals of Applied Biology. Cambridge, 76:311-318.

DARBY, R.J. e P.J. SALTER, 1976. A tecnique for osmotically pre-treating and germinating quantities of small. seeds. Annals of Applied Biology. Cambridge, 83:313-315.

DIAS, A.S., 1978. Influência do tamanho e do peso da semente de arroz (oryza sativa L.) sobre a germinação, o vigor e a produção de grãos. ESALQ -USP. Piracicaba, SP. 101 ... (Dissertação de Mestrado).

DIAS, R.A., 1973. Aplicação e vermiculita em alfobres. Sil vicultura. São Paulo, 8:99-109. 
DUNHAM, C.W., 1967. Nutrition of greenhouse crops in soils with added peatmoss and vermiculite. Proceeding of the Ame. rican Society for Horticultural Science. Michigan, 90:462-466 .

ELLS, E.J., 1963. The influence of treating tomato seed with nutrient solutions on emergence rate ka seediling yrowth • Proceeding of the American Society for Horticultural Science. Michigan, $83: 684-687$.

FERNANDES, P. de S.; E.S. BAENA; C.J. COUTINHO e J.C. GONÇALVES, 1983. Produção de mudas de Eucalyptus saligna em bandejas de isopor. Silvicultura. São Paulo, 282-284.

FERREIRA, F.A.; J.F. PEDROSA e J.L. AGUIAR, 1977a. Diferentes composições do leito de sementeira sobre a produção de mudas de couve--flor. In: Anais do XVII Congresso da Sociedade de Olericultura do Brasil. Juazeiro, BA, 86-87.

1977b. Diferentes

composições do leito de sementeira sobre a produção de mudas de tomateiro em solos da baixada do sul de Minas Gerais. In: Anais do XVII Congresso da sociedade de Olericultura do Brasil. Juazeiro, BA, 157-158. 
FERREIRA, F.A. e J.L. AGUIAR, 1978. Efeito de diferentes com posições do leito de sementeira sobre a produção de mudas e bulbos de cebola (Allium cepa L.) em solos da baixada de Lambari. Projeto Olericultura. Relatório Anual 76/77. Belo Horizonte, EPAMIG, 150.

FREY, D.R., 1981. Composed solid waste and its use for germi nating seeds. Plant Propagation. U.S.A., 27(3):10-11.

GRAY, D., 1976. The effect of time to emergence on head weight and variation in head weight at maturity in lettuce (Lactuca sativa L.). Annals of Applied Biology. Cambridge, $82: 569-575$

e J.R.A. STECKEL, 1977. Effects of pre sowing treat ments of seeds on the germination and establishment of pars nips. Journal of Horticultural Science. London, 52:525$-534$.

1978a. Comparison of fluid drilling and conventional establishment techniques on seedling emergence and crop uniformity in lettuce. Journal of Horticultural Science. London, 53:23-30. 
GRAY, D. , 1978b. The effect of sowing pregerminated .... of lettuce (Lactuca sativa L.) on seedling emergence. Annals. of Applied Biology. Cambrigde, 88:185-195.

e P.J. SALTER, 1980. Fluid drilling. Grower Gride no 13. Grower Books. London. $28 \mathrm{p}$.

GRIMSHAW, P.J., 1981. Fluid drilling. A British perspective. American Vegetable Grower. December, 9-12.

GULL, D.D.; S.L. LOCASCIO e S.R. KOSTEWICZ, 1977. Composition of greenhouse tomatoes as affected by cultivar, production media and fertilizer. Proceeding of the Florida state Hor ticultural Society. Florida, 90:395-397.

HARRIOTT, B.L., 1970. A packaged environment system for precision planting. Transaction of ASAE. Michigan, 1.8:650$-653$.

HIGA, R.C.V., 1982. Estaquia de erva-mate (I lex paraguariensis ST HILL), In: 49 Congresso Florestal Brasileiro. Anais. Belo Horizonte. p. 42 .

IRMAN, J.W., 1968. Precision planting. A reality for vegeta bles. Agricultural Engineering. St. Joseph, 49(6):344-345.

KAHN, A., 1960. Promotion of lettuce seed germination by gibberelin. Plant Physiology 포: 333-339. 
KOSTEWICZ, S.R. e S.J. LOCASCIO, 1976. Effects of production media, cultivar and fertilizer on yield of greenhouse toma toes. Proceeding. of the Florida State Horticultural Socie ty. Florida, 89:129-131.

LIPE, W.N. e J.A. SKINNER, 1979. Effect of sowing pregermina ted onions seeds in cold soil on time of emergence, maturity and yield. HortScience. Michigan, 14(3):238-239.

LONGDEN, P.C.; M.C. JOHNSON; R.J. DARBY e P.J. SALTER, 1979. Establishment and growth of sugar beet affected by seed treatment and fluid drilling. Journal of Agricultural Science. Cambridge, 93:541-552.

MCCOY, D.; F.E. ROBINSON; H. JOHNSON JR.; R.G. CURLEY; C.BROOKS; G. GIANNINI e F. LE BARON, 1969. Precision planting of lettuce. Journal of the American Society for Horticultural Science. Michigan, $\underline{94}(4): 344-345$.

MEDINA, P.V.L. e F.A.A. COUTO, 1971. Efeito da profundidade de plantio, do tipo de leito e do método de semeadura sobre a germinação do quiabeiro (Hibiscus esculentus). Re vista de Olericultura. Viçosa, MG, 1l:68.

MILLER, W.F. e C. SOOTER, 1967. Improving emergence:of pelleted vegetable seed. Transaction of the ASAE. Michigan, 10:658-666. 
MINAMI, K. (s.d.). Utilização do vermiculita na floricultura e paisagismo (mimeografado). $3 \mathrm{p}$.

PAULI, A.W. e B.L. HARRIOTT, 1968. Lettuce seed selection and treatment for precision planting. Agricultural Engineering. St. Joseph, $49(1): 18-24$.

RANZANI, G.; O. FREIRE e T. KINJO, 1966. Carta de Solos do Município de Piracicaba. Piracicaba, SP. 85 p.

ROCHELLE, L.A. e N.A. VELLO, 1982. Germinação de sementes e desenvolvimento de plântulas de cultivares de cucurbitā-ceas. Anais da Escola Superior de Agricultura "Luiz de Queiroz". Piracicaba, SP, $39(1): 277-286$.

ROBINSON, F.E. e G.F. WORKER JR., 1966. Factors affecting the emergence of sugar beets in an irrigated desert enviroment. Agronomy Journal. Madison, 58:433-436.

; K.S. MAYBERRY e H. JOHNSON JR., 1975. Emergence and yield of lettuce from coated seed. Transaction of ASAE. Michigan, 18:650-653.

e , 1976. Seed coating precision planting and sprinkler irrigation for optimum stand establishment. Agronomy Journal. Madison, 68:694-695. 
SALTER, P.J., 1978a. Fluid drilling of the pregerminated seeds: progress and possibilities. Acta Horticulturae. United Kingston, 83:245-249.

1978b. Teckniques and properts for fluid drilling of vegetable crops. Acta Horticulturae. United Kingston, 72:101-108.

SCHOEN, J.F. e N. KRAMER, 1981. Effects of differents types of sand and vermiculite grades on the test tube method for evaluating preinoculated seed. Crop Science. Madison, 21 (2) : 347-348.

SETEZER, J., 1967. Atlas climätico ecológico do Estado de São Paulo. Comissão Interestadual da Bacia do Paraná. Uruguai. CESP, SP. $61 \mathrm{p}$.

SKINNER, C.G. e W. SHIVE, 1959. Stimulation of lettuce seed germination by 6-(substituted purines). Plant Physiology, $34: 1-3$.

STILI, S.M., 1977. Comparison of chysanthemum growth in pine bark commercial soilless mixes. HortScience. Michigan, $12(6): 573-574$. 
TAYLOR, A.G., 1977. Comparative performance of pregerminated high moisture content and dry vegetable seed in greenhouse and field studies. Journal of Seed Tecnology. Launsing, 2 (1) $: 51-52$.

TAYLOR, A.G.; S.W. SEARCY, J.E. MOTES e L.O. ROTH, 1981. Separation, singularion and precision planting of germinated seed. HortScience. Michigan, 16(2):198-200.

THOMPSON, R.C., 1946. Germination of endive seed ( Cichoriuem indivia) at high temperature stimuled by thiourea and by wather treatments. Journal of the American Society for Horticultural Science. Michigan, 47:323-326.

VAN DOREN, D.M. e J.E. HENRY, 1973. Study ways to increase sugar beet emergence. Ohio Report. Ohio, 58(1):11-13.

VIGGIANO, J.; A.A. de MACEDO; P.T. de CARVALHO,.J.A.C. PENNA e F.A.A. CoUTo, 1973. Estudo sobre a influêncía do tama nho da semente de tomate (Lycopersicon esculentum Mill. ) na produção. Revista de Olericultura. Viçosa, MG, 13: 81-82 .

WOLFE, D.M. e W.L. SIMS, 1982. Effects of osmoconditioning and fluid drilling of tomato seed on emergence rate and final yield. HortScience. Michigan, 17:936-937. 
ZINK, F.W., 1955. Studies with pelleted lettuce seed. Proceeding of the American Society for Horticultural Science. Michigan, $65: 335-341$. 
$-65-$

$\begin{array}{llllllll}A & P & \hat{E} & N & D & I & C & E\end{array}$ 
TABELA 15. Dados meteorológicos dos meses de agosto/setembro de 1982, ESALQ, Piracicaba - SP, durante o, período em.que foram realizados os experimentos.

\begin{tabular}{|c|c|c|c|}
\hline DIA & $\begin{array}{l}\text { PRECIPITAÇÃO } \\
(\mathrm{mm})\end{array}$ & $\begin{array}{l}\text { UMIDADE REIA } \\
\text { TIVA }(\%)\end{array}$ & $\begin{array}{c}\text { TEMPERATURA MÉDIA } \\
{ }^{\circ} \mathrm{C}\end{array}$ \\
\hline $25 / 08$ & - & 64,0 & 20,1 \\
\hline $26 / 08$ & - & 68,4 & 23,2 \\
\hline $27 / 08$ & - & 73,0 & 22,9 \\
\hline $28 / 08$ & 6,5 & 79,5 & 21,1 \\
\hline $29 / 08$ & 4,5 & 81,4 & 22,6 \\
\hline $30 / 08$ & - & 69,9 & 22,0 \\
\hline $31 / 08$ & - & 78,7 & 23,1 \\
\hline $01 / 09$ & - & 79,3 & 23,0 \\
\hline $02 / 09$ & - & 74,9 & 21,6 \\
\hline $03 / 09$ & - & 74,9 & 21,6 \\
\hline $04 / 09$ & - & 64,8 & 21,9 \\
\hline $05 / 09$ & 1,4 & 75,1 & 22,4 \\
\hline $06 / 09$ & - & 75,8 & 22,9 \\
\hline $07 / 09$ & - & 71,6 & 17,5 \\
\hline $08 / 09$ & - & 71,0 & 16,5 \\
\hline $09 / 09$ & - & 68,0 & 17,4 \\
\hline $10 / 09$ & - & 58,9 & 16,4 \\
\hline $11 / 09$ & - & 51,5 & 19,4 \\
\hline $12 / 09$ & - & 48,8 & 21,3 \\
\hline $13 / 09$ & - & 67,0 & 23,8 \\
\hline $14 / 09$ & - & 65,0 & 23,1 \\
\hline
\end{tabular}


TABELA 16. Dados meteorológicos dos meses de abril e maio de 1984, ESALQ - Piracicaba, SP, durante o período em que foram realizados os experimentos.

\begin{tabular}{|c|c|c|c|}
\hline DIA & $\begin{array}{c}\text { PRECIPITAÇÃO } \\
\text { (Im) }\end{array}$ & $\begin{array}{l}\text { UMIDADE REIA } \\
\text { TIVA (\%) }\end{array}$ & $\begin{array}{c}\text { TEMPERATURA MEDIA } \\
{ }^{\circ} \mathrm{C}\end{array}$ \\
\hline $06 / 04$ & - & 78,4 & 20,0 \\
\hline $07 / 04$ & 3,7 & 79,8 & 21,2 \\
\hline $08 / 04$ & - & 75,1 & 22,6 \\
\hline $09 / 04$ & - & 70,8 & 23,2 \\
\hline $10 / 04$ & - & 69,1 & 22,6 \\
\hline $11 / 04$ & - & 70,4 & 20,1 \\
\hline $12 / 04$ & - & 68,2 & 19,6 \\
\hline $13 / 04$ & - & 69,0 & 21,5 \\
\hline $14 / 04$ & - & 67,8 & 22,8 \\
\hline $15 / 04$ & - & 92,5 & 23,6 \\
\hline $16 / 04$ & - & 82,1 & 21,0 \\
\hline $17 / 04$ & - & 76,6 & 23,3 \\
\hline $18 / 04$ & - & 70,5 & 24,4 \\
\hline $19 / 04$ & - & 70,7 & 25,8 \\
\hline $20 / 04$ & - & 80,5 & $25,0$. \\
\hline $21 / 04$ & - & 74,5 & 24,4 \\
\hline $22 / 04$ & 9,2 & 82,2 & 24,4 \\
\hline $23 / 04$ & - & 73,8 & 25,0 \\
\hline $24 / 04$ & 20,1 & 89,8 & 25,5 \\
\hline $25 / 04$ & - & 83,4 & 22,8 \\
\hline $26 / 04$ & - & 81,4 & 17,3 \\
\hline $27 / 04$ & - & 85,7 & 21,4 \\
\hline $28 / 04$ & - & 79,5 & 22,5 \\
\hline $29 / 04$ & - & 84,6 & 24,1 \\
\hline $30 / 04$ & 1,0 & 83,5 & 31,5 \\
\hline $01 / 05$ & 0,5 & 87,6 & 22,1 \\
\hline $02 / 05$ & 9,1 & 98,2 & 21,2 \\
\hline
\end{tabular}

